\title{
Divergence in physiological factors affecting swimming performance between anadromous and resident populations of brook charr Salvelinus fontinalis
}

\author{
Crespel Amelie ${ }^{1,{ }^{*}}$, Dupont-Prinet A. ${ }^{1}$, Bernatchez L. ${ }^{2}$, Claireaux Guy ${ }^{3}$, Tremblay R. ${ }^{1}$, Audet C. ${ }^{1}$
}

${ }^{1}$ Institut des sciences de la mer de Rimouski (ISMER); Université du Québec à Rimouski (UQAR); 310 des Ursulines Rimouski QC G5L 3A1, Canada

${ }^{2}$ Institut de Biologie Intégrative et des Systèmes (IBIS), Pavillon Charles-Eugène-Marchand, 1030, Avenue de la Médecine, Local 1145; Université Laval; Québec QC G1V 0A6 ,Canada

${ }^{3}$ LEMAR UMR 6539 (UBO-CNRS-IRD-Ifremer); Institut Universitaire Européen de la Mer, Unité PFOMARN - Centre de Bretagne; 29280 Plouzané ,France

* Corresponding author : Amelie Crespel, email address : amelie.crespel@gmail.com

\begin{abstract}
:
In this study, an anadromous strain $(\mathrm{L})$ and a freshwater-resident $(\mathrm{R})$ strain of brook charr Salvelinus fontinalis as well as their reciprocal hybrids, were reared in a common environment and submitted to swimming tests combined with salinity challenges. The critical swimming speeds (Ucrit) of the different crosses were measured in both fresh (FW) and salt water (SW) and the variations in several physiological traits (osmotic, energetic and metabolic capacities) that are predicted to influence swimming performance were documented. Anadromous and resident fish reached the same Ucrit in both FW and SW, with Ucrit being 14\% lower in SW compared with FW. The strains, however, seemed to use different underlying strategies: the anadromous strain relied on its streamlined body shape and higher osmoregulatory capacity, while the resident strain had greater citrate synthase (FW) and lactate dehydrogenase (FW, SW) capacity and either greater initial stores or more efficient use of liver (FW, $\mathrm{SW}$ ) and muscle (FW) glycogen during exercise. Compared with $\mathrm{R} \cap \mathrm{L} \hat{\jmath}$ hybrids, $\mathrm{L}+\mathrm{R} \widehat{\jmath}$ hybrids had a $20 \%$ lower swimming speed, which was associated with a $24 \%$ smaller cardio-somatic index and higher physiological costs. Thus swimming performance depends on cross direction (i.e. which parental line was used as dam or sire). The study thus suggests that divergent physiological factors between anadromous and resident $S$. fontinalis may result in similar swimming capacities that are adapted to their respective lifestyles.
\end{abstract}

Keywords : hybrids, local adaptation, metabolism, swimming performance. 


\section{Introduction}

During their life cycle, many fishes species undergo migrations between habitats that are essential for completing their life cycle (e.g. reproductive, nursery and feeding habitats). These movements occur on temporal and spatial scales ranging from daily to annual and from a few metres to thousands of kilometres (McDowall, 1997; Klemetsen et al., 2003; Fraser \& Bernatchez, 2005; Kitano et al., 2012). The environmental 
conditions encountered largely determine the physiological cost associated with these migratory movements.

In salmonids, swimming ability and support capacities (e.g. oxygen transport, cardiovascular performance and energy metabolism) fundamentally contribute to the success of migratory movements (Eliason et al., 2011; Eliason \& Farrell, 2016). In these species, migratory behaviour involves rapid transitions between fresh water and sea water and osmoregulatory ability is a strong determinant in the success of such movements (McDowall, 1997; Peake et al., 1997; Claireaux \& Audet, 2000; Boula et al., 2002; Wagner et al., 2006). Links between swimming ability and capacity to maintain body fluid osmolality have been amply documented in fishes (Brauner et al., 1992, 1994; Nelson et al., 1996; McKenzie et al., 2001a,b). For instance, in Coho salmon Oncorhynchus kisutch 1 lbaum 1792) smolts and juvenile Adriatic sturgeon Acipenser naccarii Bonaparte 36 , an acute increase in water salinity associated with an increase of plasma ions and osmolality was found to be directly related to a reduction in maximum sustainable swimming speed (Brauner et al., 1992, 1994; McKenzie et al., 2001a,b). Conversely, the lack of/significant effects of ambient salinity on European seabass Dicentrarchus labrax (L. 1758) swimming and cardiac performance was linked to an exceptional capacity of this species to maintain plasma osmolality and tissue water content when exposed to an acute change in ambient salinity (Chatelier et al., 2005).

In salmonids, migratory behaviour has evolved as an obligate phase in the life cycle of some species whereas it is facultative in others (McDowall, 1997; Klemetsen et al., 2003; Fraser \& Bernatchez, 2005; Thériault et al., 2007; Arai \& Goto, 2008). In brook charr Salvelinus fontinalis (Mitchill 1814), the ancestral form of anadromy is now facultative (Castric \& Bernatchez, 2003; Curry et al., 2010) and different migratory patterns exist depending on the biotic and abiotic conditions in the native environment of a population (Castric \& Bernatchez, 2003). The anadromous S. fontinalis population of the Laval River (L) $\left(48^{\circ} 44^{\prime} \mathrm{N} ; 69^{\circ} 05^{\prime} \mathrm{W}\right)$ on the north shore of the St Lawrence Estuary migrates to fresh water for reproduction and overwintering and to salt water in summer for feeding. These fish can thrive in habitats encompassing a wide range of environmental conditions, from low to high salinity $(1-34)$, temperature $\left(5-18^{\circ} \mathrm{C}\right)$ and water velocities (Boula et al., 2002; Curry et al., 2006). The Rupert population (R) is a strictly freshwater resident $S$. fontinalis population originating from the Rupert River $\left(51^{\circ} 05^{\prime} \mathrm{N} ; 73^{\circ} 41^{\prime} \mathrm{W}\right)$ near Lake Nemiscau (near James Bay in north-western Québec). These fish always live in cold fresh water and migrate from the river to lakes for reproduction (MAPA-Pêcheries, 1992). In addition to living in two different environments and having different lifestyles, previous genetic studies revealed a pronounced genetic differentiation between these two populations (mean \pm S.E. $F$ st $=0 \cdot 427 \pm 0 \cdot 020$; Martin et al., 1997), as well as important differences in gene expression when reared in a same environment (Bougas et al., 2010). It is not known, however, whether these differences are accompanied by a divergence in their swimming capacity.

Previous studies on salmonids have revealed that different lifestyles among species or populations may result in differences in their swimming ability (Taylor \& McPhail, 1985; Hawkins \& Quinn, 1996; Peake et al., 1997). In Atlantic salmon Salmo salar (L. 1758), anadromous individuals possess greater sustained swimming ability than landlocked ones, possibly related to their different morphology (the anadromous form has a more fusiform body shape than the landlocked one) and migratory histories (Peake et al., 1997). When swimming tests were conducted in common environments, 
the differences between populations remained (Taylor \& Foote, 1991), suggesting a genetic basis for swimming performance and thus a potential for evolutionary adaptation. In three-spined stickleback Gasterosteus aculeatus L. 1758, comparisons of swimming performance in freshwater resident and anadromous populations, both in Europe (Tudorache et al., 2007) and North America (Dalziel et al., 2011), have shown that anadromous fish had a greater swimming performance than the freshwater residents. In the North American populations, this difference is genetically based (Dalziel et al., 2011). Understanding the genetic and physiological bases of evolutionary change in swimming capacity in S. fontinalis could provide further insight into the functional bases of differential adaptation in swimming capacity of fishes (Odell et al., 2003; Collin \& Fumagalli, 2011; Dalziel et al., 2011).

Hybridization between different populations may also provide important information on the genetic basis of swimming performance and the degree of divergence between populations. For example, measuring traits in F1 hybrids could reveal the relative importance of additive or non-additive genetic effects in the expression of performance (Dalziel et al., 2011). When populations are genetically closer, hybrids tend to express additive genetic effects and show intermediate performance compared with their parental lines. On the contrary, when populations are genetically divergent and adapted to their own environments, hybrids may express non-additive genetic effects due to complex genetic associations (Falconer \& Mackay, 1996; Edmands, 1999; Cooke et al., 2001; Cooke \& Philipp, 2005; Stelkens et al., 2009). Non-additive genetic effects have been reported for various morphological and physiological traits such as size, survival and other fitness-related traits in rainbow trout Oncorhynchus mykiss (Walbaum 1792) (Tymchuk et al., 2009), O. kisutch (Emlen, 1991) and S. fontinalis (Granier et al., 2011; Crespel et al.,2012) and also in swimming performance in largemouth bass Micropterus salmoides (Lacépède 1802) (Cooke et al., 2001). The occurrence of non-additive genetic effects controlling fitness-related traits thus provide further evidence for evolutionary divergence among the populations studied. The occurrence of non-additive genetic effects in swimming performance, however, and its underlying physiological basis among populations with different migratory lifestyles has rarely been investigated.

Whether anadromous fish are better swimmers than freshwater residents has been tested, hypothesizing that this trait would be a major fitness component in migratory fish. In addition to condition factor and energy reserve levels, a whole range of physiological factors can affect fish swimming capacity, thus the measurement of these variables gives information on their relative contributions. Blood oxygen-carrying capacity was inferred from blood haematocrit and haemoglobin concentration, leading to the calculation of the mean cellular haemoglobin concentration. The capacities of experimental populations to mobilize energy reserves to fuel working muscles were compared by measuring blood glucose as well as liver and white muscle glycogen content. For the same reason, white muscle and heart pyruvate and lactate concentrations were also assessed. The activities of white muscle lactate dehydrogenase (LDH) and citrate synthase (CS) were measured because these enzymes are important regulators of aerobic and anaerobic metabolism responding to substrate:product ratios. These measurements provided insight into the relative contribution of aerobic $v$. anaerobic pathways to meet the energy needs associated with swimming. Since the capacity to maintain plasma osmotic and ionic characteristics is a key factor affecting fish swimming capacity, gill $\mathrm{Na}^{+}-\mathrm{K}^{+}-$ATPase activity was also assessed. 


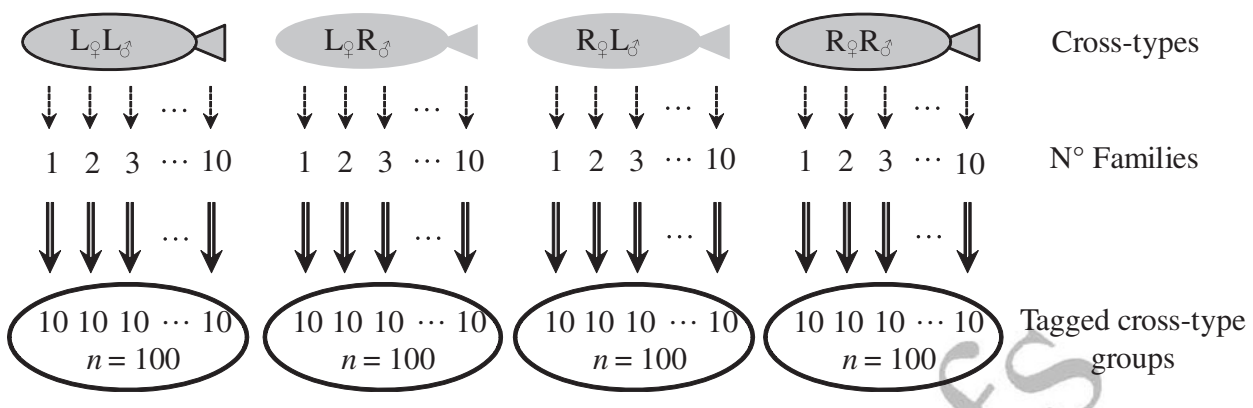

FIG. 1. Schematic diagram of the cross-types used to test swimming performance in purebred erosses of Salvelinus fontinalis (L, Laval anadromous strain; R, Rupert freshwater-resident strain) and of their reciprocal hybrids. The first letter of the cross-type indicates the dam and the second letter the sire. 2 ious families within cross-types $(n=10) ; \Downarrow$, the number of fish sampled from the different families $(n=100)$.

The occurrence of non-additive effects in the hybrids was investigated to obtain additional insight into the genetic divergence between anadromous and resident strains. For this, two alternative hypotheses were tested. First, non-additive effects are present in hybrids, indicating a divergence for swimming performance between the two populations of origin and creating complex genetic associations during adaptation. Alternatively, the hybrids do not express non-additive effects, indicating that swimming performance is supported by compatible genes in the two populations of origin.

\section{MATERIALS AND METHODS}

\section{EXPERIMENTAL ANIMALS}

Experiments were conducted using two strains of wild S. fontinalis (Laval and Rupert) and the corresponding hybrid crosses. Breeders were third generation fish produced in captivity at the Station aquicole (ISMER-UQAR, Rimouski, QC, Canada) and at the Laboratoire de Recherche en Sciences Aquatiques (LARSA, Université Laval, Québec, QC, Canada). Four cross-types

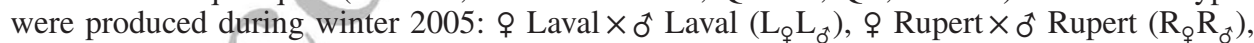

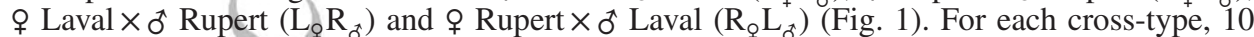
full-sib families were obtained through single-pair mating. All families were reared under similar conditions in recirculating fresh water (FW) at LARSA from egg incubation (January) to exogenous feeding (at the end of the summer). Water temperature was maintained at $6^{\circ} \mathrm{C}$ during egg incubation and at $8^{\circ} \mathrm{C}$ after hatching. Photoperiod followed the natural seasonal cycle $\left(46^{\circ} 45^{\prime} \mathrm{N}\right)$ and fish were fed according to commercial charts.

In September, fish were transferred to the Station aquicole ISMER-UQAR, where they were reared under natural temperature and photoperiod $\left(48^{\circ} 30^{\prime} \mathrm{N}\right)$ conditions in running dechlorinated FW. They were fed daily (food ration of $1 \%$ fish wet mass) with commercial dry pellets. In March, 10 fish from each family (100 fish per cross-type) were tagged using fingerling tags (Floy Tag Inc.; www.floytag.com) (Fig. 1).

\section{THE FLUME}

The swimming tests were performed using a circular flume (with a linear swimming section) designed to provide non-turbulent water flow (Redjah et al., 2010). Briefly, a variable-speed motor propelled the water at a constant velocity. Plastic honeycomb structures 
TABLE I. Summary of experimental design: experimental groups of purebred and hybrid Salvelinus fontinalis used to test the repeatability of the swimming tests and perform the critical swimming speed $\left(U_{\text {crit }}\right)$ test in salt water $(\mathrm{SW})$ and the control groups with different fish used to perform the critical swimming speed $\left(U_{\text {crit }}\right)$ test in fresh water $(\mathrm{FW})$

\begin{tabular}{|c|c|c|c|c|c|c|c|}
\hline & \multicolumn{2}{|c|}{$\mathrm{L}_{\phi} \mathrm{L}_{\hat{\sigma}}$} & \multicolumn{2}{|c|}{$\mathrm{L}_{\phi} \mathrm{R}_{\hat{\phi}}$} & \multicolumn{2}{|c|}{$\mathrm{R}_{\phi} \mathrm{L}_{\hat{\sigma}}$} & $\mathrm{R}_{\varphi} \mathrm{R}_{\hat{\phi}}$ \\
\hline & Repeats & Fish & Repeats & Fish & Repeats & Fish & Repeats Fish \\
\hline \multicolumn{8}{|l|}{ Experimental group } \\
\hline Repeatability test 1 (FW) & 2 & 15 & 2 & 15 & 2 & 15 & \\
\hline Repeatability test 2 (FW) & 2 & 15 & 2 & 15 & 2 & 15 & 15 \\
\hline Repeatability test 3 (FW) & 2 & 15 & 2 & 15 & 2 & 15 & 15 \\
\hline$U_{\text {crit }}(\mathrm{SW})$ & 2 & 15 & 2 & 15 & 2 & 15 & 15 \\
\hline \multicolumn{8}{|l|}{ Control group } \\
\hline$U_{\text {crit }}(\mathrm{FW})$ & 1 & 10 & 1 & 10 & 1 & & 10 \\
\hline
\end{tabular}

L, Laval anadromous strain; R, Rupert freshwater-resident strain. The first letter of the cross-type indicates the dam and the second letter the sire.

and deflectors were inserted in the circulation loop upstream from the swimming chamber $(23 \mathrm{~cm} \times 37 \mathrm{~cm} \times 22.3 \mathrm{~cm})$ to promote rectilinear flow and a uniform velocity profile. An acoustic Doppler velocimeter (type $16 \mathrm{MHz}$ MicroADV, Sonteck; www.sontek.com) was used to calibrate water velocity to voltage output from the motor controller. The flume was supplied with fully aerated and thermoregulated $\left(6 \cdot 8^{\circ} \mathrm{C}\right.$, range $\left.\pm 0 \cdot 3^{\circ} \mathrm{C}\right)$ water at a flow rate of $101 \mathrm{~min}^{-1}$.

\section{VALIDATION TEST AND CRITICAL SWIMMING SPEED PROTOCOL}

To validate the swimming challenge procedure, two subgroups of 15 tagged fish per cross-type were submitted to three consecutive swim tests in FW with a $4 \mathrm{~h}$ recovery period between tests 1 and 2 and a $16 \mathrm{~h}$ recovery period between tests 2 and 3, which is in line with the capacity of salmonids to fully recover from exhaustion (45-90 min; Jain et al., 1998; Lee et al., 2003; Tierney \& Farrell, 2004). Cross-types were tested separately, with subgroups of fish swimming together in each trial (Table I). The repeatability of individual performances was confirmed (Table II; $P>0.05)$ as was the fish swimming performance ranking $(P>0.05)$.

Following transfer into the swimming chamber, fish were left undisturbed for $30 \mathrm{~min}$ at a water speed of $5.5 \mathrm{~cm} \mathrm{~s}^{-1}$ (i.e. 0.5 standard length $\mathrm{s}^{-1} ; L_{\mathrm{S}} \mathrm{s}^{-1}$ ). Following this acclimation period, fish were submitted to a stepwise increase of water velocity from $5 \cdot 5$ to $11 \cdot 0$ to $16 \cdot 5 \mathrm{~cm} \mathrm{~s}^{-1}$ at

TABLE II. Repeatability of mean \pm S.E. critical swimming speed $\left(U_{\text {crit }}\right)$ in the purebred strains

\begin{tabular}{|c|c|c|c|c|}
\hline$n$ & $\begin{array}{c}\mathrm{L}_{\phi} \mathrm{L}_{\text {क }} \\
30\end{array}$ & $\begin{array}{c}\mathrm{L}_{\phi} \mathrm{R}_{\oint^{\dagger}} \\
30\end{array}$ & $\begin{array}{c}\mathrm{R}_{\mathrm{o}_{\mathrm{o}}} \mathrm{L}_{\mathrm{o}^{\prime}} \\
\end{array}$ & 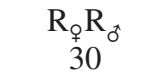 \\
\hline$U_{\text {crit }} 1\left(L_{S}, \mathrm{~s}^{-1}\right)$ & $2 \cdot 85 \pm 0 \cdot 21$ & $2 \cdot 83 \pm 0 \cdot 20$ & $3 \cdot 08 \pm 0 \cdot 13$ & $2 \cdot 24 \pm 0 \cdot 11$ \\
\hline$U_{\text {crit }} 2\left(L_{\mathrm{S}}, \mathrm{s}^{-1}\right)$ & $2 \cdot 59 \pm 0 \cdot 18$ & $2 \cdot 65 \pm 0 \cdot 17$ & $3 \cdot 00 \pm 0 \cdot 17$ & $1 \cdot 90 \pm 0 \cdot 11$ \\
\hline$U_{\text {crit }} 3\left(L_{\mathrm{S}}, \mathrm{s}^{-1}\right)$ & $2 \cdot 22 \pm 0 \cdot 15$ & $2 \cdot 47 \pm 0 \cdot 10$ & $3 \cdot 13 \pm 0 \cdot 18$ & $2 \cdot 44 \pm 0 \cdot 11$ \\
\hline
\end{tabular}

The repeatability tests were done in fresh water. $U_{\text {crit }}$ among trials were not statistically different.

L, Laval anadromous strain; R, Rupert freshwater-resident strain (The first letter of the cross-type indicates the dam and the second letter the sire.); $n$, the number of individuals per swim test; $L_{S}$, standard length. 
TABLE III. Mean \pm S.E. standard length $\left(L_{\mathrm{S}}\right)$, body mass $\left(M_{\mathrm{B}}\right)$, condition factor $(K)$ and cardio-somatic index $\left(I_{\mathrm{C}}\right)$ of two purebred strains of Salvelinus fontinalis and their reciprocal hybrids used for swimming challenges and biochemical samples

\begin{tabular}{|c|c|c|c|c|}
\hline$n$ & $\begin{array}{c}\mathrm{L}_{\mathrm{q}} \mathrm{L}_{\text {๙ }} \\
38\end{array}$ & $\begin{array}{c}\mathrm{L}_{\mathrm{Q}} \mathrm{R}_{\mathrm{C}^{+}} \\
\end{array}$ & $\begin{array}{c}\mathrm{R}_{\rho} \mathrm{L}_{\mathrm{O}^{+}} \\
40\end{array}$ & 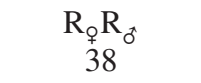 \\
\hline$L_{\mathrm{S}}(\mathrm{cm})$ & $11 \cdot 08 \pm 0 \cdot 16^{\mathrm{a}}$ & $13 \cdot 29 \pm 0 \cdot 34^{\mathrm{c}}$ & $12 \cdot 00 \pm 0 \cdot 24^{\mathrm{b}}$ & $11.94 \pm 0 \cdot 21^{b}$ \\
\hline$M_{\mathrm{B}}(\mathrm{g})$ & $11 \cdot 11 \pm 0 \cdot 61^{\mathrm{a}}$ & $21.98 \pm 1.98^{c}$ & $13.63 \pm 0.91^{\mathrm{a}}$ & $17 \cdot 30 \pm 0.95^{b}$ \\
\hline$K\left(\mathrm{~g} \mathrm{~cm}^{-3}\right)$ & $0.79 \pm 0.02^{a}$ & $0.86 \pm 0.02^{b}$ & $0.76 \pm 0.03^{a}$ & $0.98 \pm 0.02^{c}$ \\
\hline$I_{\mathrm{C}}(\%)$ & $0 \cdot 15 \pm 0 \cdot 01^{\mathrm{ab}}$ & $0 \cdot 14 \pm 0 \cdot 01^{\mathrm{a}}$ & $0 \cdot 18 \pm 0 \cdot 01^{\mathrm{b}}$ & $0.16 \pm 0.01^{\mathrm{ab}}$ \\
\hline
\end{tabular}

Different superscript lower case letters indicate significant differences among cross-types $(P<0 \cdot 05)$.

L, Laval anadromous strain; R, Rupert freshwater-resident strain (the first letter of the cross-type indicates the dam and the second letter the sire.); $n=$ the number of individuals.

5 min intervals and then to $22 \cdot 0,27 \cdot 5,33 \cdot 0,38 \cdot 5,44 \cdot 0,49 \cdot 5$ and in some cases, $55 \cdot 0 \mathrm{~cm} \mathrm{~s}^{-1}$ at $15 \mathrm{~min}$ intervals. Fish were considered to be fatigued when they were unable to remove themselves from the screen situated downstream from the swimming chamber. At that time, fish were removed from the swim chamber, identified (tag reading) and placed in their original rearing tank. The corresponding water velocity and time were recorded. The critical swimming speed $\left(U_{\text {crit }}, L_{\mathrm{S}} \mathrm{s}^{-1}\right)$ was calculated according to Brett (1964)

$$
U_{\text {crit }}=\left[U+\left(T T_{i}^{-1}\right) U_{i}\right] L_{\mathrm{S}}^{-1}
$$

where $U$ is the highest velocity maintained for the whole interval $\left(\mathrm{cm} \mathrm{s}^{-1}\right), T$ is the time elapsed at fatigue velocity (s), $T_{i}$ is the prescribed interval time between each speed increment (300 or $900 \mathrm{~s})$ and $U_{i}$ is the velocity increment $\left(5.5 \mathrm{~cm} \mathrm{~s}^{-1}\right)$. No correction for blocking effect was applied since the total cross-sectional area of the fish did not exceed 5\% of the swimming chamber (Bell \& Terhune, 1970).

\section{EVALUATION OF/SWIMMING CAPACITY}

Following the assessment of measurement repeatability, the fish used for the validation tests were directly transferred into salt water (SW; salinity $20,6 \cdot 8^{\circ} \mathrm{C}$, range $\pm 0 \cdot 3^{\circ} \mathrm{C}$ ). Salinity was adjusted by mixing St Lawrence estuarine water (salinity $31-32$ ) with dechlorinated FW before it entered rearing tanks. After a $48 \mathrm{~h}$ acclimation period, fish subgroups were submitted to the $U_{\text {crit }}$ test as described above (Table I). As one fish reached exhaustion, it was rapidly removed from the flume and anaesthetized in $0.12 \mathrm{~g} \mathrm{l}^{-1}$ MS-222 until opercular movements ceased ( $c$. $1.5-2 \mathrm{~min}$ ) for blood and tissue samplings. Control fish were submitted to the same $U_{\text {crit }}$ procedure described above in FW, but only one group of 10 fish per cross-type swam together for these trials (Table I). Fish were not fed for $48 \mathrm{~h}$ before their transfer to the swimming chamber. To avoid circadian bias in hormonal measurements, SW and FW $U_{\text {crit }}$ tests began at $1400 \mathrm{~h}$ and were completed by $1630 \mathrm{~h}$.

\section{BLOOD AND TISSUE SAMPLING}

Following measurement of $L_{\mathrm{S}}$ (to the nearest $\left.0 \cdot 1 \mathrm{~cm}\right)$ and body mass $\left(M_{\mathrm{B}}\right.$, to the nearest $0 \cdot 1 \mathrm{~g}$ ) (Table III), blood was drawn by caudal puncture using ammonium-heparinized syringes. A small quantity of blood was kept for haematocrit and haemoglobin measurements and the remainder was centrifuged at $7200 \mathrm{~g}$ for $3 \mathrm{~min}$. Plasma aliquots were frozen in liquid nitrogen and stored at $-80^{\circ} \mathrm{C}$ for further analyses. Gill filaments, liver, heart and three pieces of epaxial muscle (one for each biochemical analysis) were excised and liver and heart $\left(M_{\mathrm{H}}\right)$ wet mass were recorded. The 
cardio-somatic index $\left(I_{\mathrm{C}}\right)$ was calculated as $I_{\mathrm{C}}=100 M_{\mathrm{H}} M_{\mathrm{B}}{ }^{-1}$. Tissue samples were immediately frozen on dry ice and then stored at $-80^{\circ} \mathrm{C}$ prior to analysis. An additional piece of epaxial dorsal muscle was excised, weighed and dried for $72 \mathrm{~h}$ at $70^{\circ} \mathrm{C}$ for calculation of water content. Because body shape can affect swimming performance, condition factor $(K)$ was estimated according to the equation $K=100 M_{B} L_{\mathrm{S}}{ }^{-3}$.

Plasma osmolality was measured with an Advanced Micro-osmometer (model 3MO, Advanced Instruments Inc.; www.aicompanies.com), blood haemoglobin concentration was determined by Drabkin's method (Drabkin \& Austin, 1935), plasma glucose was measured by enzymatic determination (Alexander \& Griffiths, 1993) and cortisol levels were measured using a cortisol ${ }^{125}$ I RIA kit (MP Biomedicals; www.mpbio.com). Mean cellular haemoglobin concentration (MCHC) was calculated using haematocrit data. Gill $\mathrm{Na}^{+}-\mathrm{K}^{+}-$ATPase capacity was measured using the micro-method described in Seigler et al. (1996).

Muscle and liver glycogen contents were determined according to the amyloglucosidase digestion method (Carr \& Neff, 1984) followed by glucose concentration determination. Heart lactate, heart pyruvate, white muscle lactate and white muscle pyruvate concentrations were measured using enzymatic assays (Henry, 1968). Muscle samples were weighed and homogenized in 10 volumes of cold $100 \mathrm{mM}$ imidazole-HCl buffer ( $\mathrm{pH} \mathrm{7.4)} \mathrm{and} \mathrm{LDH} \mathrm{and} \mathrm{CS}$ capacity were measured according to Le François \& Blier (2003). The Michaelis constant $\left(K_{\mathrm{m}}\right)$ was evaluated using different substrate concentrations, i.e. from 0.01 to $0.5 \mathrm{mM}$ oxaloacetate for CS and from 0.25 to $1 \mathrm{mM}$ pyruvate for $\mathrm{LDH}$ and calculated using a non-linear regression procedure (GraphPad Prism 5, GraphPad Software Inc.; www.graphpad.com).

\section{STATISTICAL ANALYSES}

It was assumed that fish were observed independently and that the number of d.f. in the statistical analysis should be the number of fish. This was supported by the repeatability of individual performances (consecutive swim trials on the same groups of fish; Table II, $P>0 \cdot 05$ ) as well as fish swimming performance ranking $(P>0 \cdot 05)$.

Spearman rank order correlation and ANOVA with repeated measures were used to determine the repeatability of fish swimming performance rank. Normality and homogeneity of variances were verified by Kolmogorov-Smirnov and Brown-Forsythe tests, respectively. Muscle pyruvate concentration data were not normally distributed, so data were ranked and statistical procedures were applied on ranks (Quinn \& Keough, 2002). Cortisol data were $\log _{10}$ transformed and lactate:pyruvate ratio data were square-root transformed to avoid heteroscedasticity. The different variables were analysed using two-way ANCOVA with salinity and cross-type as fixed effects and body mass as the covariable. If no covariance effect was found, a two-way ANOVA was run. The presence of non-additive effects was determined by the presence of significant differences between the mean trait values of hybrids compared with the mean traits of both parental strains (Bryden et al., 2004). When significant factor effects were found, a posteriori Tukey comparison of means tests $(\alpha=0.05)$ were used (Sokal $\&$ Rohlf, 1981). For those variables for which transformations failed to give homogeneity of variances, the Games and Howell test was used (Sokal \& Rohlf, 1981). The least significant difference (LSD) test was used for muscle pyruvate concentration. All statistical analyses were performed with Statistica software (Statsoft 6; wwW.statsoft.com).

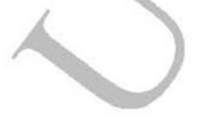

\section{RESULTS}

The different cross-types used in this study were significantly different in terms of length and body mass even though they were raised under similar conditions and were the same age (Table III). $K$ was $20 \%$ lower in anadromous $S$. fontinalis $\left(\mathrm{L}_{\phi} \mathrm{L}_{\delta^{\circ}}\right)$ than in resident fish $\left(\mathrm{R}_{\odot} \mathrm{R}_{\sigma^{\prime}}\right.$ ) (Table III). $K$ of $\mathrm{R}_{\odot} \mathrm{L}_{\sigma^{+}}$hybrids was similar to the paternal line $\left(\mathrm{L}_{\odot} \mathrm{L}_{\delta^{*}}\right)$, while that of $\mathrm{L}_{\uparrow} \mathrm{R}_{\phi^{*}}$ hybrids was intermediate compared with parental lines. The cardio-somatic indexes $\left(I_{C}\right)$ of the two purebred strains were similar and intermediate

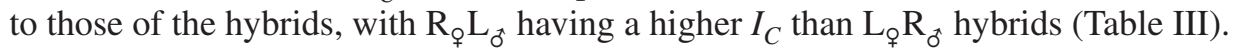




\section{SWIMMING CHALLENGES}

Critical swimming speed varied according to both cross-type and salinity with no significant interaction between the two factors and body mass did not influence $U_{\text {crit }}$ (Table IV). While $U_{\text {crit }}$ values were similar in pure crosses of the anadromous and resident strains, swimming performance was $18 \%$ lower in $\mathrm{L}_{\odot} \mathrm{R}_{\phi^{-}}$compared with the reciprocal $\mathrm{R}_{\mathrm{\rho}} \mathrm{L}_{\mathrm{0}}$. Also, swimming performance was significantly higher in $\mathrm{FW}$ (mean \pm S.E. $\left.3 \cdot 50 \pm 0 \cdot 13 L_{\mathrm{S}} \mathrm{s}^{-1}\right)$ compared with SW $\left(3 \cdot 00 \pm 0 \cdot 07 L_{\mathrm{S}} \mathrm{s}^{-1}\right)$ (Fig. 2).

\section{STRESS AND OSMOTIC RESPONSE}

Cortisol concentration was similar among all groups that underwent the swim challenge both in FW and SW (Table IV), with an overall mean \pm S.E. of $6 \cdot 25 \pm 0.60 \mu \mathrm{g} \mathrm{dl}^{-1}$. Even though significant treatment effects were found (Table IV), multiple comparison tests did not indicate differences in plasma glucose between the different cross-types and salinity groups. The overall mean \pm S.E. plasma glucose was $0.90 \pm 0.04 \mathrm{mg} \mathrm{ml}^{-1}$.

Muscle water content varied according to cross-type and salinity with no significant interaction between the two (Table IV) and it was negatively correlated to body mass. The $\mathrm{L}_{\phi} \mathrm{L}_{\delta}$ fish had significantly higher muscle water content (c. 1.7\%) compared with fish from the other cross-types (Table IV). Overall, muscle water content was close to $2 \%$ lower in fish challenged in SW than in fish challenged in FW. A significant interaction between cross-type and salinity was observed for plasma osmolality as was a significant negative body mass covariance effect (Table IV). In FW, plasma osmolality was $4.9 \%$ higher in the $\mathrm{L}_{\odot} \mathrm{R}_{\delta^{*}}$ cross-type than in the $\mathrm{L}_{\odot} \mathrm{L}_{\sigma^{*}}$ fish [Fig. 3(a)]. Swimming to exhaustion in SW was associated with an increase in plasma osmolality in all groups of fish, but plasma osmolality was $6 \%$ higher in resident fish than in the two hybrid cross-types [Table IV and Fig. 3(a)]. $\mathrm{Na}^{+}-\mathrm{K}^{+}-$ATPase capacity was similar among cross-types that swam in FW/significant interaction between factors with no significant covariance effect; Table IV), but activity was almost three times higher in $R_{\odot} R_{\odot}$ individuals than in the other three cross-types in SW challenges [Fig. 3(b)].

Blood haematocrit varied according to cross-type (Table IV) and was positively correlated to body mass. Blood haematocrit was $12 \%$ lower in $\mathrm{L}_{\phi} \mathrm{L}_{\boldsymbol{O}^{*}}$ fish (the smallest cross-type) than in the other cross-types [Fig. 4(a)]. Blood haemoglobin varied according to both cross-type and salinity (significant interaction between factors) and a significant positive body mass covariance effect was noted (Table IV). In SW, blood haemoglobin concentration was highest in $\mathrm{L}_{\odot} \mathrm{R}_{\widehat{\sigma}^{*}}$ hybrids while no difference could be seen among cross-types in fish that swam in FW [Fig. 4(b)]. The resulting MCHC differed among cross-types but not salinities: there was no significant covariate effect

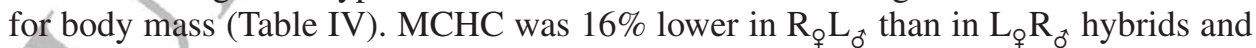
$\mathrm{MCHC}$ levels in hybrids were similar to their respective maternal line [Fig. 4(c)].

\section{ENERGY RESERVES}

A significant interaction between cross-type and salinity was observed for muscle glycogen content with no $M_{\mathrm{B}}$ covariance effect (Table IV). After fish were challenged in FW, muscle glycogen content was $64.4 \%$ lower in anadromous and $\mathrm{R}_{\odot} \mathrm{L}_{\phi^{*}}$ hybrids than in $R_{\odot} R_{\delta^{*}}$ fish [Fig. 5(a)]. The muscle glycogen content in the other hybrid was intermediate to those of the parental lines. Following exhaustion in SW, muscle glycogen content was similar among cross-types (Fig. 5). Within each cross-type, muscle 
SWIMMING PERFORMANCE IN S. FONTINALIS

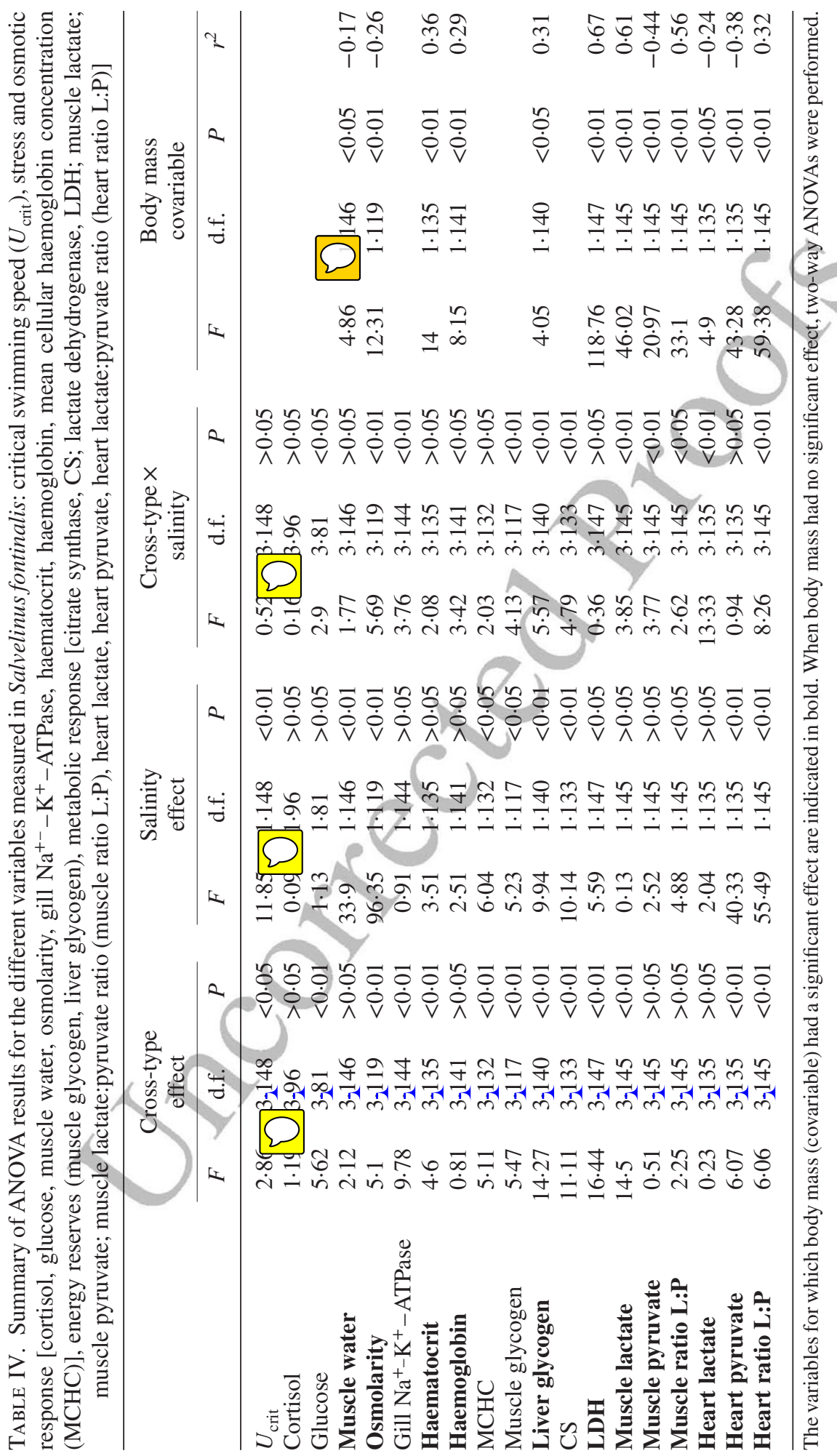




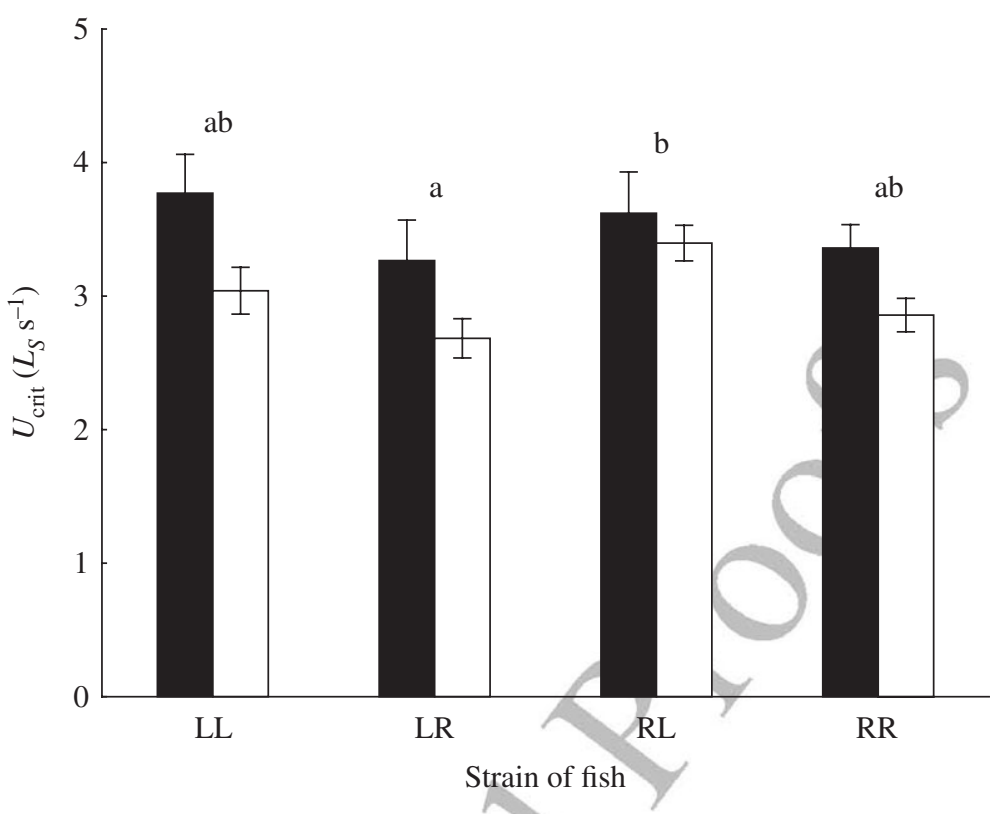

FIG. 2. Mean \pm S.E. critical swimming speeds $\left(U_{\text {crit }}\right)$ of the two purebred strains (L, Laval anadromous strain; R, Rupert freshwater-resident strain) of Salvelinus fontinalis and their reciprocal hybrids in fresh ( $\mathbf{\square})$ and salt water $(\square)$. The first letter of the cross-type indicates the dam and the second letter the sire. Different lower case letters indicate significantly different means among cross-types $(P<0 \cdot 05)$. No significant interaction between cross-type and salinity was found. $L_{S}$, Standard length.

glycogen content was similar whether swimming challenges were performed in FW or SW. A significant interaction between cross-type and salinity was also observed for liver glycogen content along with a significant positive body mass covariance effect (Table IV). Exhaustion in SW or FW only had a distinct effect in $\mathrm{L}_{\odot} \mathrm{R}_{\mathrm{o}^{\star}}$ hybrids, for which liver glycogen was $60 \%$ lower after the SW challenge compared with the concentration in fish exercised in FW [Fig. 5(b)]. In FW-exhausted fish, liver glycogen was $c .60 \%$ lower in Laval fish than in the three other cross-types, while liver glycogen concentration in $\mathrm{SW}$ was $56 \%$ lower in $\mathrm{L}_{\varphi} \mathrm{L}_{\sigma^{+}}$and $\mathrm{L}_{\varphi} \mathrm{R}_{\sigma^{+}}$than in the two other cross-types.

\section{METABOLIC RESPONSE}

There was a significant interaction between cross-type and salinity for white-muscle CS capacity (Table IV). In FW, CS capacity was $27 \%$ higher in the Rupert fish $\left(R_{O} R\right)$ than in the other cross-types, while no cross-type difference was observed in SW-exhausted fish [Fig. 6(a)]. No salinity effect was present within cross-types. CS $K_{\mathrm{m}}$ was also similar between fish challenged in FW $\left(0.012 \mathrm{mMl}^{-1}\right)$ and SW $\left(0.011 \mathrm{mM}^{-1}\right)$. White muscle LDH capacity varied with both cross-type and salinity (but without significant interaction) and a significant positive $M_{\mathrm{B}}$ covariance effect was present (Table IV). The LDH capacity was $48 \%$ lower in $\mathrm{L}_{\odot} \mathrm{L}_{0}$ fish than in the three other cross-types [Fig. 6(b)] and LDH $K_{\mathrm{m}}$ was similar for fish swim-challenged in $\mathrm{FW}\left(0.79 \mathrm{mMl}^{-1}\right)$ and $\mathrm{SW}\left(1.00 \mathrm{mMl}^{-1}\right)$. 

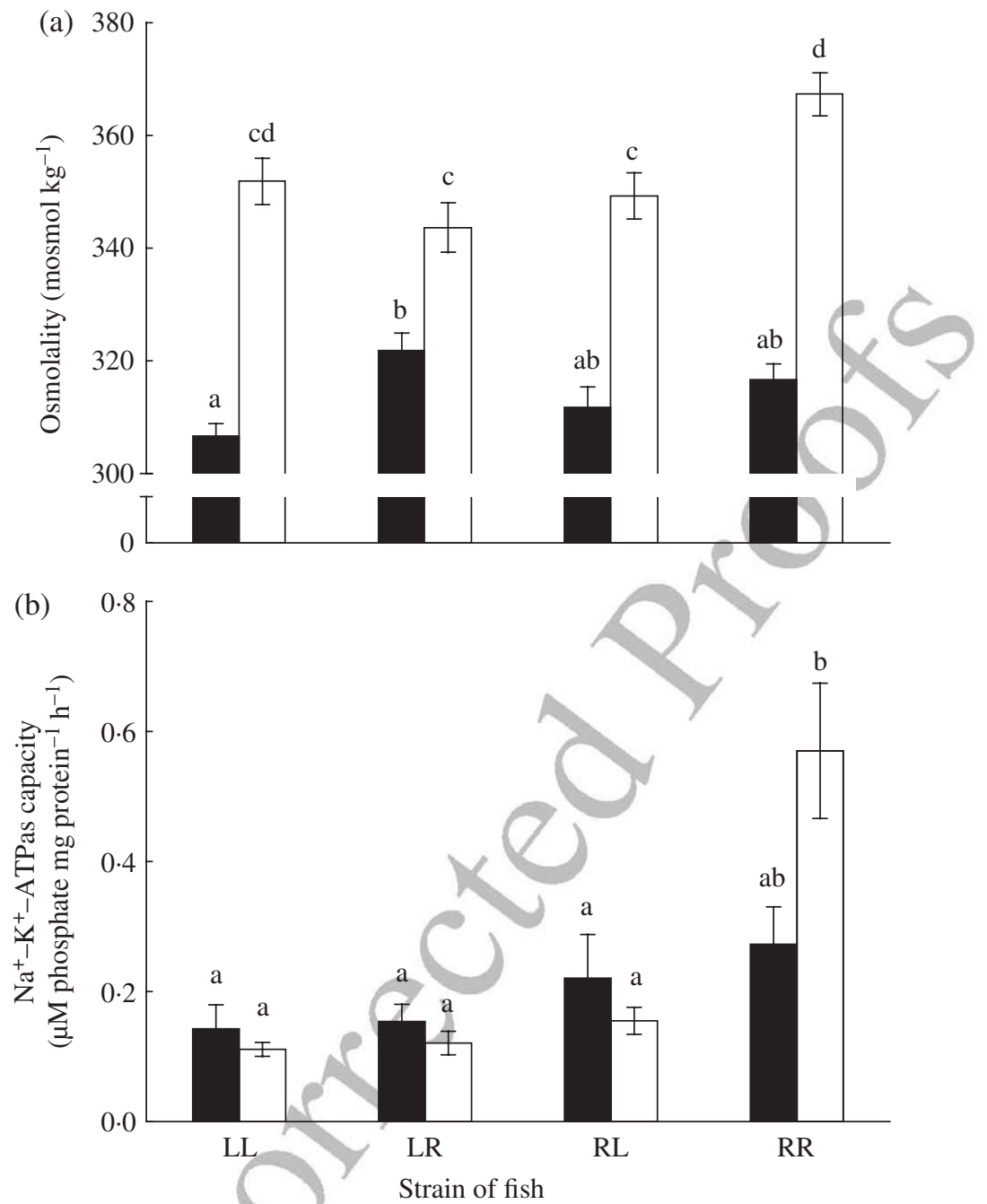

FIG. 3. Mean \pm S.E. (a) plasma osmolality and (b) gill $\mathrm{Na}^{+}-\mathrm{K}^{+}-$ATPase specific activity in two purebred strains (L, Laval anadromous strain; R, Rupert freshwater-resident strain) of Salvelinus fontinalis and their reciprocal hybrids in fresh $(\square)$ and salt water $(\square)$. The first letter of the cross-type indicates the dam and the second letter the sire. Different letters indicate significantly different means $(P<0 \cdot 05)$.

Muscle lactate concentration was different among cross-types and salinity trials (Table IV) and there was a positive correlation with body mass (Table IV). The $\mathrm{L}_{\phi} \mathrm{L}_{\delta^{\circ}}$

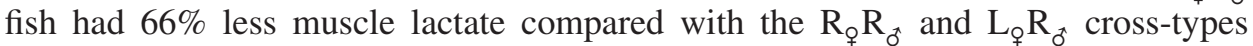
while the concentration in $\mathrm{R}_{\odot} \mathrm{L}_{{ }^{*}}$ hybrids was intermediate [Fig. 7(a)]. Within each cross-type, no difference was present between swimming trials in FW or SW. A significant interaction between cross-type and salinity was observed for muscle pyruvate content along with a significant negative correlation with $M_{\mathrm{B}}$ (Table IV). After the FW challenge, muscle pyruvate content in $\mathrm{L}_{\rho} \mathrm{R}_{\mathrm{o}^{*}}$ hybrids was 3.7 times lower than in the $R_{\odot} R_{\delta^{*}}$ cross-type [Fig. 7(b)], but there was no difference among cross-types 

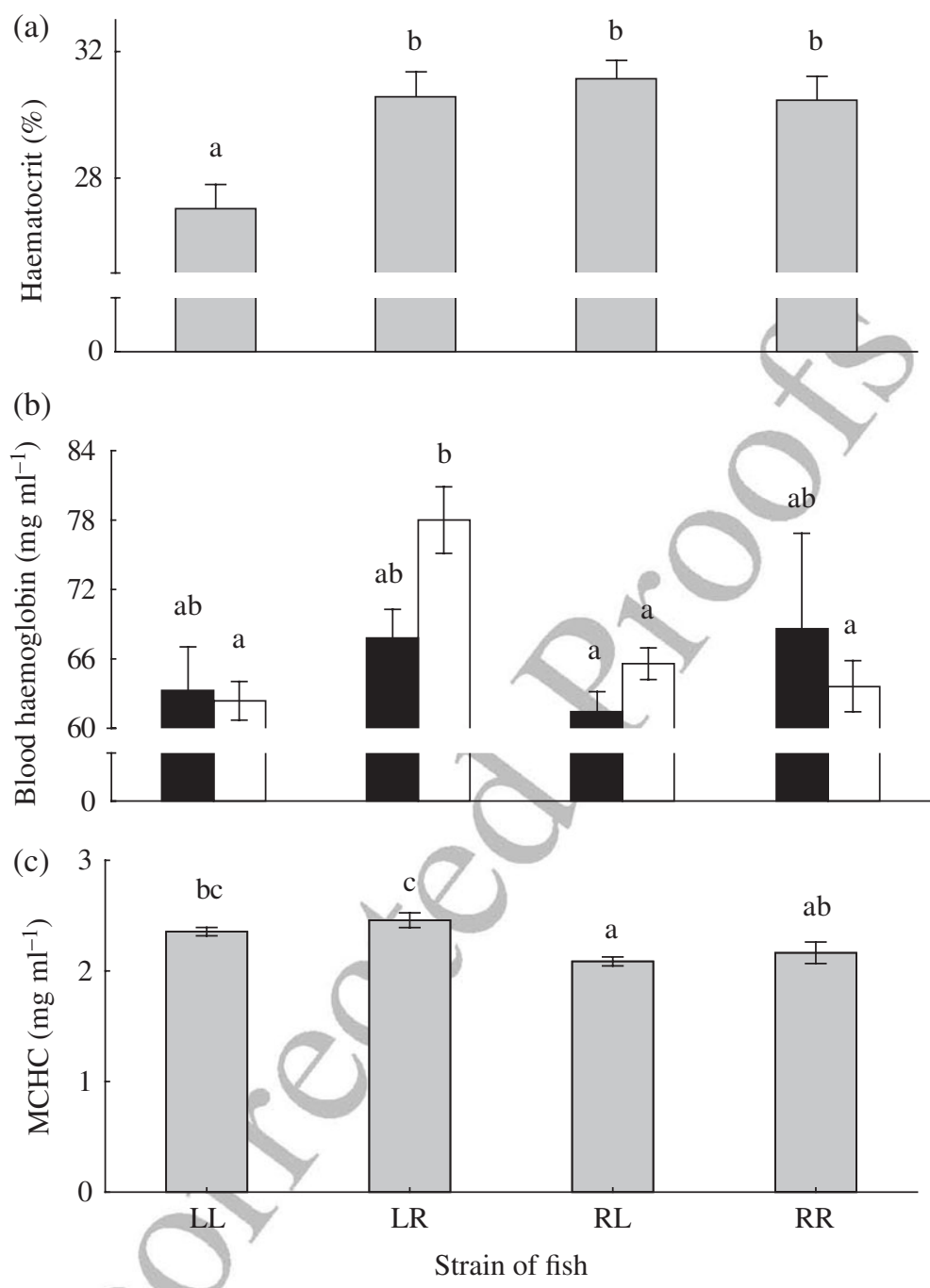

FIG. 4. Mean \pm S.E. (a) haematocrit, (b) blood haemoglobin and (c) mean cellular haemoglobin concentration (MCHC) in two purebred strains (L, Laval anadromous strain; R, Rupert freshwater-resident strain) of Salvelinus fontinalis and their reciprocal hybrids in fresh $(\square)$, salt water $(\square)$, or combined fresh and saltwater data ( $\square$ ). The first letter of the cross-type indicates the dam and the second letter the sire. Different lower case letters indicate significantly different means $(P<0.05)$.

following exhaustion in SW. Within cross-types, only $\mathrm{L}_{\odot} \mathrm{R}_{{ }^{+}}$hybrids exhibited a significant difference in muscle lactate between FW and SW challenges: the muscle lactate:pyruvate ratio was 2.7 times higher in FW compared with SW [Fig. 7(c)] and a significant negative $M_{\mathrm{B}}$ covariance effect was observed (Table IV).

There was a significant interaction between cross-type and salinity on heart lactate content with a concomitant negative $M_{\mathrm{B}}$ covariance effect (Table IV). After challenge in $\mathrm{FW}$, the heart lactate concentration of $\mathrm{R}_{\rho} \mathrm{L}_{\mathrm{o}}$ hybrids was $37 \%$ lower than in purebred crosses [Fig. 7(d)] while it was highest in this cross-type following SW swimming 

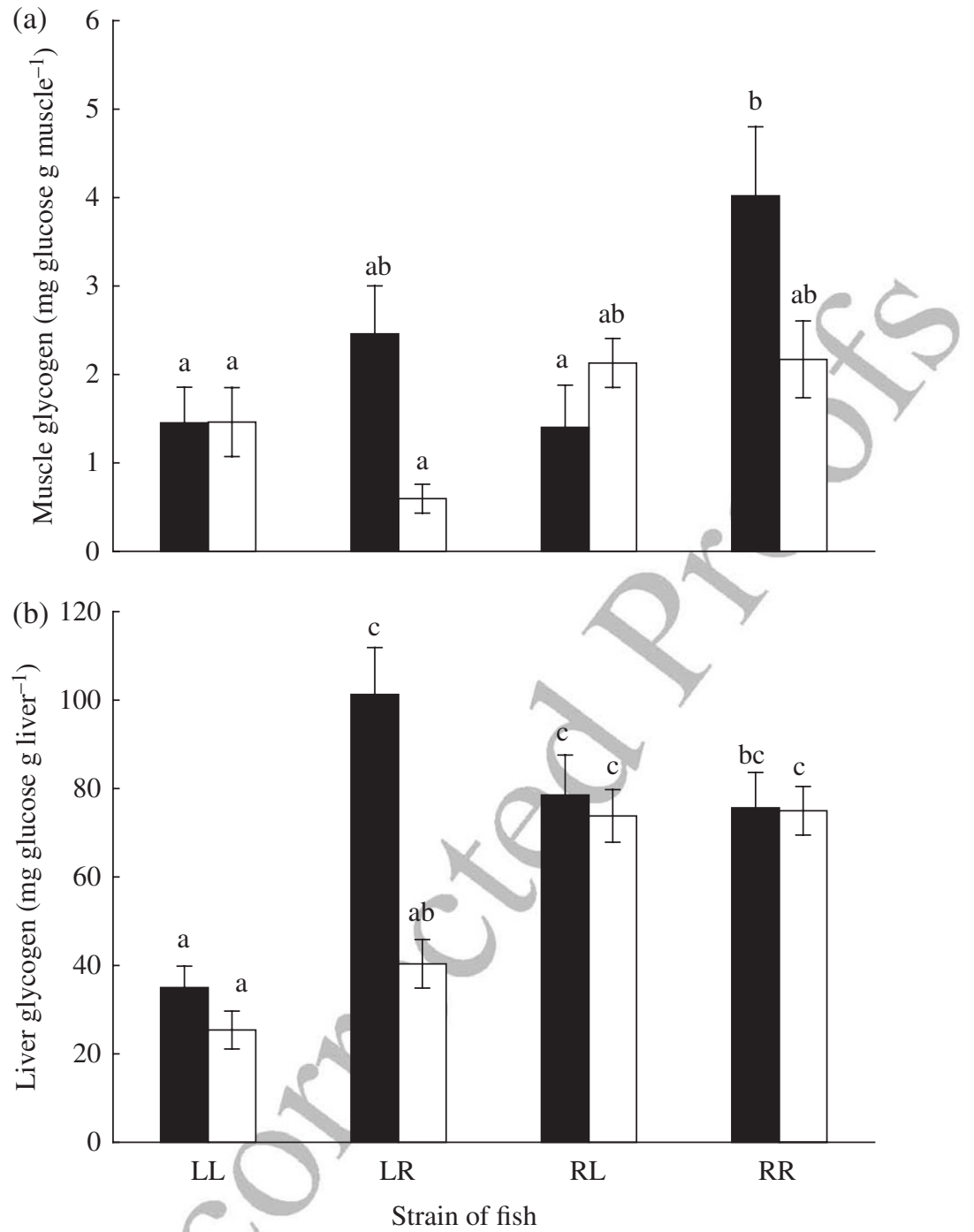

FIG. 5. Mean \pm S.E. (a) muscle and (b) liver glycogen concentration in two purebred strains (L, Laval anadromous strain; R, Rupert freshwater-resident strain) of Salvelinus fontinalis and their reciprocal hybrids in fresh (ם), salt water $(\square)$.The first letter of the cross-type indicates the dam and the second letter the sire. Different lower case letters indicate significantly different means $(P<0 \cdot 05)$.

exhaustion. Thus heart lactate concentration differed between the two environments only in the $\mathrm{R}_{\varphi} \mathrm{L}_{\delta}$ cross-type (1.9 times higher in FW than in SW). Heart pyruvate concentration also varied according to cross-type and salinity (but without interaction), with a significant negative $M_{\mathrm{B}}$ covariance effect (Table IV): it was $69 \%$ higher in $\mathrm{L}_{\varphi} \mathrm{L}_{\text {के }}$ fish than in $\mathrm{R}_{\phi} \mathrm{L}_{\diamond}$ hybrids. Globally, heart pyruvate concentration was $34.6 \%$ lower after the SW swimming challenge than after the FW challenge [Fig. 7(e)]. This resulted in the highest heart lactate:pyruvate ratio for $\mathrm{R}_{\varphi} \mathrm{L}_{\delta}$ hybrids challenged in SW (twice as high as the overall mean ratios of all other challenged fish) [Fig. 7(f)]. 

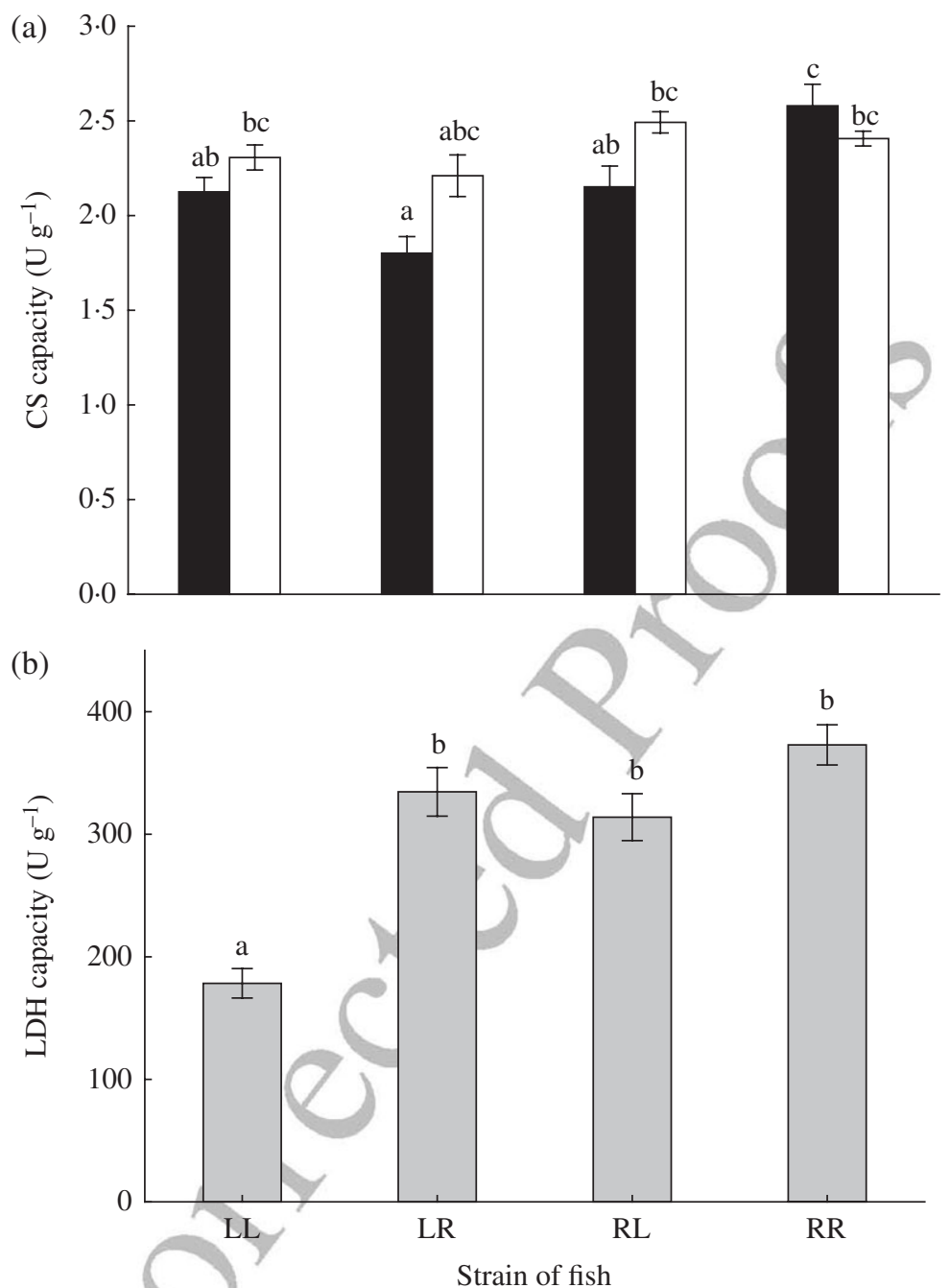

FIG. 6. Mean \pm S.E. (a) citrate synthase (CS) and (b) lactate dehydrogenase (LDH) capacity in two purebred strains (L, Laval anadromous strain; R, Rupert freshwater-resident strain) of Salvelinus fontinalis and their reciprocal hybrids in fresh ( $\square$ ), salt water $(\square)$, or combined fresh and saltwater data ( $\square$ ). The first letter of the cross-type indicates the dam and the second letter the sire. Different lower case letters indicate significantly different means $(P<0 \cdot 05)$.

\section{DISCUSSION}

The main objective of this study was to test for the occurrence of functional divergence in the factors affecting swimming performance (estimated by $U_{\text {crit }}$ ) between pure strains and reciprocal hybrids issued from two wild populations of $S$. fontinalis having different migratory lifestyles (anadromous Laval strain $v$. freshwater resident Rupert strain). Pure cross types had similar swimming performance in FW and swimming performance was reduced by $14 \%$ following abrupt transfer to SW in both anadromous and resident fish. The pure cross types, however, reached similar swimming speeds using 

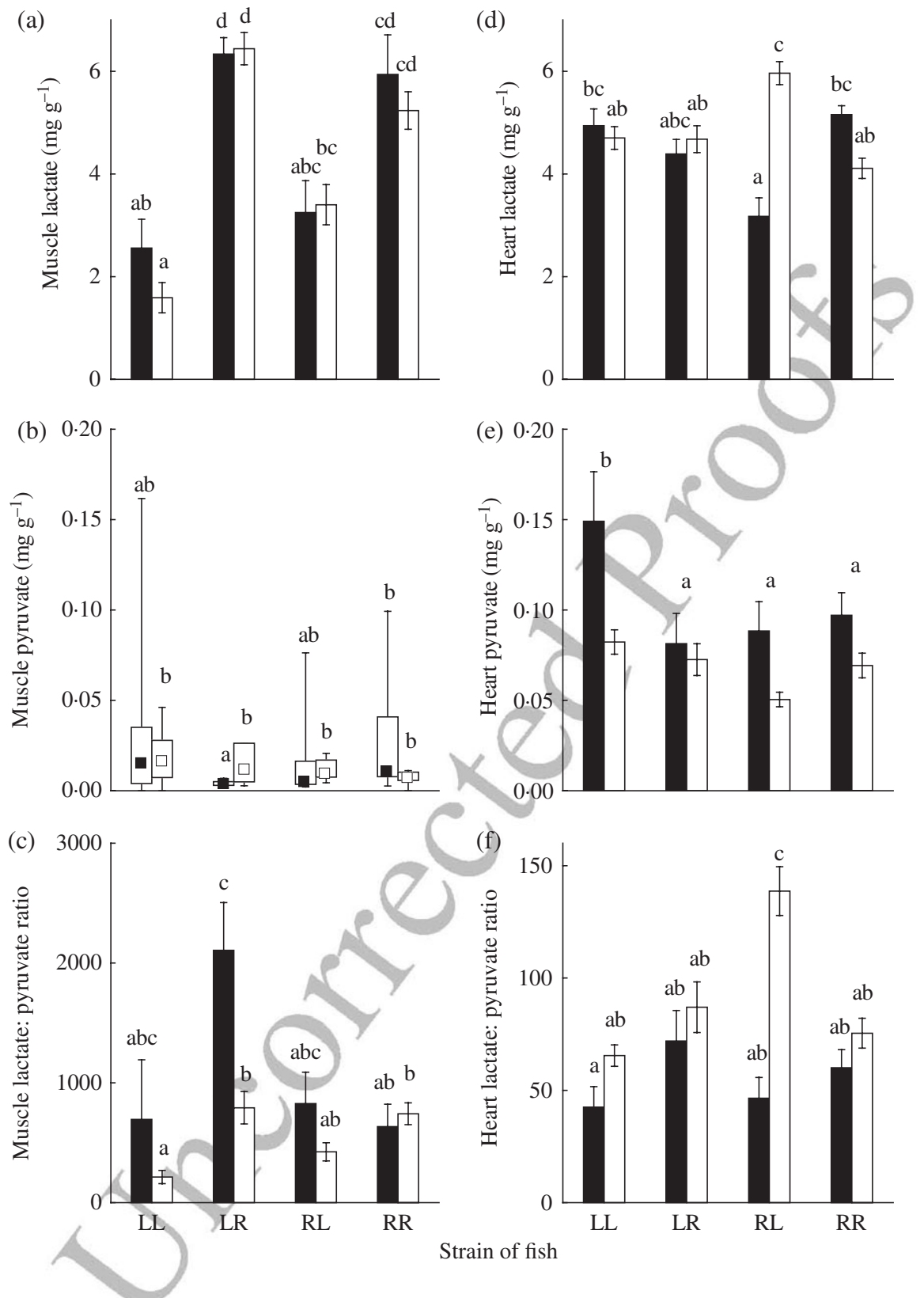

FIG. 7. Mean \pm S.E. (a) muscle lactate, (b) box plot of muscle pyruvate ( $\square$, fresh and $\square$ saltwater medians within box of middle two quartiles and whiskers for range) and mean \pm s.E. (c) muscle lactate:pyruvate ratio, (d) heart lactate, (e) heart pyruvate and (f) heart lactate:pyruvate ratio in two purebred strains (L, Laval anadromous strain; R, Rupert freshwater-resident strain) of Salvelinus fontinalis and their reciprocal hybrids in fresh $(\square)$, salt water $(\square)$. The first letter of the cross-type indicates the dam and the second letter the sire. Different lower case letters indicate significantly different means $(P<0 \cdot 05)$. Muscle pyruvate concentration data were not normally distributed and statistical analyses were carried out on ranks, but to facilitate comparison with other studies, data are presented using median and range. The muscle lactate:pyruvate ratio data were square-root transformed prior to statistical analysis, but to facilitate comparisons with other studies, arithmetic data are presented. 
different physiological strategies, suggesting different genetically-based physiological solutions to the same functional challenge. While no evidence was found for extreme non-additive genetic effects (i.e. heterosis or outbreeding depression) in hybrids, sig-

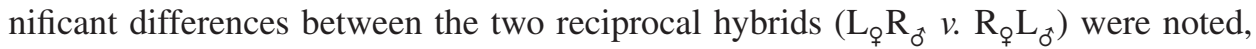
with lower performance in $\mathrm{L}_{\odot} \mathrm{R}_{\mathrm{\sigma}^{\circ}}$.

\section{PURE STRAINS}

Fishes swimming performance is controlled by a number of physiological, morphological and behavioural traits, all of which interact and involve potential trade-offs (Walker, 2010; Dalziel et al., 2011; Marras et al., 2013). Considering the principle of many-to-one mapping, many different combinations of traits can generate equivalent performance and multiple underlying factors can affect a single quantitative trait (Wainwright et al., 2005; Walker, 2010; Dalziel et al., 2011).

Condition-factor data are consistent with previous studies, which showed that anadromous fishes are more streamlined than resident fishes (Taylor \& Foote, 1991; Eliassen et al., 1998; Howland et al., 2001; Morinville \& Rasmussen, 2008; Dalziel et al., 2011). On that basis, the similar swimming performance of resident and anadromous fish may seem counterintuitive as the most streamlined body shape of the anadromous strain should be energetically advantageous. Swimming is energetically demanding and requires high aerobic metabolic capacity (Gamperl et al., 2002; Tudorache et al., 2008; Dalziel et al., 2011; Eliason \& Farrell, 2016). Resident fish must then compensate for the advantage that body shape conferred to anadromous fish.

Here, the results suggest that anaerobic swimming contributed more to their overall swimming performance. In both FW and SW, maximal swimming was associated with a muscle lactate concentration and an LDH capacity that was twice as high in resident compared with anadromous fish, suggesting a larger contribution of anaerobic component in the former. Despite a $20 \%$ higher white-muscle CS capacity in resident fish exercised in FW, no clear between-strain difference or pattern emerged regarding aerobic performance. It should be noted that CS activity was low in both resident and anadromous fish.

Higher glycogen storage and more efficient mobilization and utilization have been suggested to improve swimming performance ( $\mathrm{Fu}$ et al., 2011; Yang et al., 2015). During anaerobic swimming, fish white muscles rely on three endogenous fuel sources, i.e. adenosine triphosphate (ATP), phosphocreatine and glycogen. In the very first stages of white-muscle mobilization, ATP and phosphocreatine stores are rapidly exhausted (Dobson \& Hochachka, 1987) and it is glycogenolysis that then provides most of the ATP anaerobically, depleting muscle glycogen (Wood, 1991; Milligan, 1996). The Rupert fish (FW resident) may not only have reached a swimming performance similar to that of anadromous fish due to their greater anaerobic capacities, but also because of higher energy reserves. The glycogen levels in epaxial muscle and liver following FW exercise were more than twice as high in resident than in anadromous fish. The exception was the epaxial muscle of resident fish tested in SW, which may indicate greater energetic demand following this trial. Thus, the resident population compensated for its lower natural swimming ability (compared with the anadromous population) by having a higher metabolic capacity.

For species moving between FW and SW, a large osmoregulatory capacity is an additional and critically important determinant for maintaining swimming performance 
(Brauner et al., 1992; Nelson et al., 1996; McKenzie et al., 2001b; Chatelier et al., 2005). Regardless of FW rearing conditions, cross-type differences in the stress response to SW transfer were expected and a lower SW swimming performance in resident fish. Following the SW challenge, resident fish had plasma osmolality similar to anadromous fish combined with a gill $\mathrm{Na}^{+}-\mathrm{K}^{+}-$ATPase activity that was 4.4 times higher. No differences in other stress indicators, however, were observed whether fish were exercised in FW or in SW. One may ask why experimental animals were reared in FW. In captivity, rearing $0+$ and $1+$ year-old animals for prolonged periods in SW greatly increased events of opportunistic myxobacteria infections, suggesting impaired homeostasis, which is why young stages are routinely maintained in FW (C. Audet, unpubl. data). Otherwise, 2+ years and older anadromous Laval fish (including breeders) are reared at a salinity of 20 between the beginning of June and late September, mimicking the migration pattern of this wild anadromous fish population (Curry et al., 2010).

Previous studies comparing the performance of anadromous and resident populations in different fish species showed that anadromous fishes possessed significantly greater swimming capacities than those from resident populations [O. kysutch (Taylor \& Foote, 1991); S. fontinalis, Salmo trutta L. 1758, Salmo salar L. 1758 (Peake et al., 1997); G. aculeatus (Dalziel et al., 2011; Kitano et al., 2012)]. It has been hypothesized that their exposure to fast-water habitats, which are more energetically costly, allowed the anadromous fishes to evolve more efficient swimming abilities than resident populations [O. kysutch (Taylor \& Foote, 1991); S. fontinalis, S. trutta, S. salar (Peake et al., 1997); S. fontinalis (Morinville \& Rasmussen, 2003, 2008)]. In the present study, even though the swimming performance was similar between anadromous and freshwater resident fish, the results indicate a higher contribution of non-aerobic pathways in resident fish which suggests that they may be less adapted to sustained swimming.

\section{RECIPROCAL HYBRIDS}

Swimming performance and its underlying traits were different between the reciprocal hybrids. Compared with $\mathrm{R}_{\odot} \mathrm{L}_{0^{*}}$ hybrids, $\mathrm{L}_{\odot} \mathrm{R}_{\mathrm{o}^{\circ}}$ hybrids had a $20 \%$ lower swimming speed, which was associated with a $24 \%$ smaller cardio-somatic index, a $21 \%$ higher MCHC and a 19\% higher haemoglobin concentration when swimming in SW as well as a larger metabolic (1.9 times higher muscle lactate accumulation) and energetic (44\% less liver glycogen in $\mathrm{SW}$ ) response. $\mathrm{L}_{\wp} \mathrm{R}_{\boldsymbol{\phi}^{*}}$ hybrids thus expended greater effort and still had a lower performance than the reciprocal hybrid. Therefore, this performance depends on cross direction (parental line used as dam or sire). Such cross-direction phenomena have also been reported in M. salmoides (Cooke et al., 2001) and Chinook salmon Oncorhynchus tshawytscha (Walbaum 1792) (Falica \& Higgs, 2012), but hybrids can often be similar in their swimming performance (Hawkins \& Quinn, 1996; Dalziel et al., 2011). The reciprocal effect may be explained by various factors such as maternal or paternal effects, or genetic linkage between sex genes and performance genes. Swimming performance may be influenced by maternal effects, which are often involved in cross direction. These effects, however, generally occur during early life development (due to egg size or yolk quality) with a decrease over time and thus should probably be negligible in the present study since fish were tested at age 1+ year (Taylor \& Foote, 1991; Heath et al., 1999; Perry et al., 2004, 2005). Paternal effect could have a strong influence on swimming performance; this was the explanation given for the cross 
direction observed in $M$. salmoides and $O$. tshawytscha. The underlying genetic mechanisms of these sire effects still need to be more thoroughly investigated (Cooke et al., 2001; Evans et al., 2004; Falica \& Higgs, 2012), but could hypothetically be under genetic control. In the present study, no evidence of paternal effect was found. The genetic linkage between sex genes and genes associated with performance traits can result in sex-specific gene expression under the control of the sex-determining region (Ellegren \& Parsch, 2007; Derome et al., 2008), which might then influence the predominance of a specific parental line as dam or sire in the expression of performance. Testing this hypothesis will require further investigation. In addition, other possible effects related to the genetic architecture (e.g. pleiotropy or other genetic linkage) of swimming performance merit further investigation.

\section{GENETIC AND EVOLUTIONARY CONSIDERATIONS}

Because the experiment was conducted in a common-garden environment, differences in condition factor and physiological support features must have a genetic basis specific to each population. The different underlying traits affecting swimming performance thus have the potential to evolve under natural selection as does swimming performance itself, for which heritability has recently been estimated in D. labrax (Vandeputte et al., 2016). Similar results have been observed between different populations of Atlantic cod Gadus morhua L. 1758 originating from different salinity environments (salt and brackish water) and tested in both environments (Nelson et al., 1996). In the Nelson et al. (1996) study, swimming performance $\left(U_{\text {crit }}\right)$ did not differ between populations even though there were inter-population differences in key support performance traits such as metabolic rate and aerobic and anaerobic capacities. These populations had been separated for $<3000$ years and the authors considered that this was too short for genetic changes to have occurred under normal natural selection; they rather suggested that these inter-population differences mostly resulted from acclimation. More recent studies have suggested that genetic adaptation could occur very quickly, e.g. within a small number of generations (Reznick et al., 1997; Pearse et al., 2009; Ellner et al., 2011; Westley et al., 2013). Since the separation of the $S$. fontinalis populations used in this study occurred around 10000 years ago (Castric \& Bernatchez, 2003), it seems that such a time frame would have been sufficient for the different populations to evolve distinct genetically based physiological adaptations to cope with their respective environments.

Differences between the two populations could be the results of local adaptation to different migratory lifestyles. Since swimming performance integrates the actions of a large number of organs and supporting functions, the investigation of the variability in swimming capacity within and among populations can be considered as a relevant means to reveal elements of local adaptation (Cooke et al., 2001; Odell et al., 2003; Pon et al., 2007). Although this needs to be more rigorously investigated, ecological differences in the populations' migratory conditions (i.e. differences in fluctuations of temperature, velocity and salinity experienced by the anadromous and the resident populations in their respective environments) could have influenced the physiological processes involved in swimming performance. Since the resident population probably faces strong currents during spring, swimming ability probably remained a key determinant of fitness for freshwater residency. It should be noted, however, that the crosses in this study were only between the Rupert and the Laval strains. It is possible that 
crosses involving different anadromous and resident $S$. fontinalis populations could lead to results different from what was found here. Thus the possibility exists that the differences observed between the Rupert and Laval strains might not be linked to their migratory behaviour but to other forces shaping local adaptation. The Rupert and Laval fish used for this study were F3 fish and domestication effects may already be present (Sauvage et al., 2010). Other studies undertaken on the same families, however, have shown that they are still very different in terms of reproductive period, stress response (Crespel et al., 2011), growth, gene $\times$ environment interactions on growth (Crespel et al., 2013a) and storage and use of energy reserves (Crespel et al., 2013b). Could short-term domestication have eliminated differences in swimming capacity but maintained differences in other traits? It is a possibility that cannot be completely rejected.

One of the objectives was to test the occurrence of non-additive effects in the hybrids. No evidence of heterosis or outbreeding depression was observed. When populations are very divergent and adapted to their respective environments, this may provide evidence that their genome has evolved towards local genetic complex associations. Hybridization between divergent populations alter these associations and hybrids may thus express extreme non-additive genetic effects that can be positive (when hybrids outperform parental lines due to synergy between the genomes: heterosis) or negative (when hybrids underperform parental lines due to incompatibilities between the genomes: outbreeding depression) (Edmands, 1999; Cooke et al., 2001; Stelkens et al., 2009). Outbreeding depression has been observed in M. salmoides for the swimming performance of hybrids between two locally adapted populations, revealing a breakdown of co-adapted gene complexes (Cooke et al., 2001; Cooke \& Philipp, 2005, 2006). In the present study, which used two populations with different migratory lifestyles known to have very divergent genetic bases from both neutral (Martin et al., 1997) and functional (Bougas et al., 2010) standpoints, the occurrence of extreme non-additive genetic effects, and most specifically, outbreeding depression, would be expected (Bieri \& Kawecki, 2003; Cooke \& Philipp, 2005). This was not the case, however. The absence of pronounced non-additive effects for swimming and the underlying performance between the two populations that was found thus suggest that the extent of the genetic differences that have accumulated between these populations since their separation has not been sufficient to cause genomic incompatibilities between the parental genomes (Bieri \& Kawecki, 2003; Rosenfield et al., 2004).

The authors would like to thank I. Redjah, D. Lavallée and N. Morin for their help with sampling and technical assistance. This work was supported by a strategic research grant from the Natural Sciences and Engineering Research Council (NSERC) of Canada to L.B., C.A. and collaborators (322102-05), by Ressources Aquatiques Québec (RAQ), a research network funded by the Fonds de Recherche du Québec - Nature et Technologies, by the Society for Experimental Biology (SEB) and by The Company of Biologists (COB).

\section{References}

Alexander, R. R. \& Griffiths, J. M. (1993). Basic Biochemical Methods. New York, NY: Wiley.

Arai, T. \& Goto, A. (2008). Diverse migratory histories in a brackish water type of the ninespine stickleback, Pungitius pungitius. Environmental Biology of Fishes 83, 349-353. doi: 10.1007/s10641-008-9349-3

Bieri, J. \& Kawecki, T. J. (2003). Genetic architecture of differences between populations of cowpea weevil (Callosobruchus maculatus) evolved in the same environment. Evolution 57, 274-287. doi: 10.1554/0014-3820(2003)057 
Bougas, B., Granier, S., Audet, C. \& Bernatchez, L. (2010). The transcriptional landscape of cross-specific hybrids and its possible link with growth in brook charr (Salvelinus fontinalis Mitchill). Genetics 186, 97-107. doi: 10.1534/genetics.110.118158

Boula, D., Castric, V., Bernatchez, L. \& Audet, C. (2002). Physiological, endocrine and genetic bases of anadromy in the brook charr, Salvelinus fontinalis, of the Laval River (Quebec, Canada). Environmental Biology of Fishes 64, 229-242. doi: 10.1007/978-94-017-1352-8_21

Brauner, C. J., Shrimpton, J. M. \& Randall, D. J. (1992). Effect of short-duration seawater exposure on plasma ion concentrations and swimming performance in Coho salmon (Oncorhynchus kisutch) parr. Canadian Journal of Fisheries and Aquatic Sciences 49, 2399-2405. doi: 10.1139/f92-265

Brauner, C. J., Iwama, G. K. \& Randall, D. J. (1994). The effect of short-duration seawater exposure on the swimming performance of wild and hatchery-reared juvenile Coho salmon (Oncorhynchus kisutch) during smoltification. Canadian Journal of Fisheries and Aquatic Sciences 51, 2188-2194. doi: 10.1139/f94-220

Brett, J. R. (1964). The respiratory metabolism and swimming performance of young sockeye salmon. Journal of the Fisheries Research Board of Canada 21, 1183-1226.

Bryden, C. A., Heath, J. W. \& Heath, D. D. (2004). Performance and heterosis in farmed and wild Chinook salmon (Oncorhynchus tshawyacha) hybrid and purebred crosses. Aquaculture 235, 249-261. doi: 10.1016/j.aquaculture.2004.01.027

Carr, R. S. \& Neff, J. M. (1984). Quantitative semi-automated enzymatic assay for tissue glycogen. Comparative Biochemistry and Physiology. B 77, 447-449.

Castric, V. \& Bernatchez, L. (2003). The rise and fall of isolation by distance in the anadromous brook charr (Salvelinus fontinalis Mitchill). Genetics 163, 983-996.

Chatelier, A., McKenzie, D. \& Claireaux, G. (2005). Effects of changes in water salinity upon exercise and cardiac performance in the European seabass (Dicentrarchus labrax). Marine Biology 147, 855-862. doi: 10.1007/s00227-005-1624-7

Claireaux, G. \& Audet, C. (2000). Seasonal changes in the hypo-osmoregulatory ability of brook charr: the role of environmental factors. Journal of Fish Biology 56, 347-373. doi: 10.1006/jfbi.1999.1163

Collin, H. \& Fumagalli, L. (2011). Evidence for morphological and adaptive genetic divergence between lake and stream habitats in European minnows (Phoxinus phoxinus, Cyprinidae). Molecular Ecology 20,4490-4502. doi: 10.1111/j.1365-294X.2011.05284.x

Cooke, S. J. \& Philipp, D. P. (2005). Influence of local adaptation and interstock hybridization on the cardiovascular performance of largemouth bass Micropterus salmoides. Journal of Experimental Biology 208, 2055-2062. doi: 10.1242/Jeb.01602

Cooke, S. J. \& Philipp, D. P. (2006). Hybridization among divergent stocks of largemouth bass (Micropterus salmoides) results in altered cardiovascular performance: the influence of genetic and geographic distance. Physiological and Biochemical Zoology 79, 400-410. doi: $10.1086 / 499979$

Cooke, S. J., Kassler, T. W. \& Phillipp, D. P. (2001). Physiological performance of largemouth bass related to local adaptation and interstock hybridization: implications for conservation and management. Journal of Fish Biology 59, 248-268. doi: 10.1111/j,1095-8649.2001.tb01389.x

Crespel, A., Bernatchez, L., Garant, D. \& Audet, C. (2011). Quantitative genetic analysis of the physiological stress response in three strains of brook charr Salvelinus fontinalis and their hybrids. Journal of Fish Biology 79, 2019-2033. doi: 10.1111/j.1095-8649.2011.03149.x

Crespel, A., Audet, C., Bernatchez, L. \& Garant, D. (2012). Effects of rearing environment and strain combination on heterosis in brook trout. North American Journal of Aquaculture 74, 188-198. doi: 10.1080/15222055.2012.672884

Crespel, A., Bernatchez, L., Audet, C. \& Garant, D. (2013a). Strain specific genotypeenvironment interactions and evolutionary potential for body mass in brook charr (Salvelinus fontinalis). G3 Genes Genomes Genetics 3, 379-386. doi: 10.1534/g3.112. 005017

Crespel, A., Bernatchez, L., Garant, D. \& Audet, C. (2013b). Genetically based population divergence in overwintering energy mobilization in brook charr (Salvelinus fontinalis). Genetica 141, 51-64. doi: 10.1007/s10709-013-9705-x 
Curry, R. A., van de Sande, J. \& Whoriskey, F. G. (2006). Temporal and spatial habitats of anadromous brook charr in the Laval River and its estuary. Environmental Biology of Fishes 76, 361-370. doi: 10.1007/s10641-006-9041-4

Curry, A., Bernatchez, L., Audet, C. \& Whoriskey, F. (2010). The origins and persistence of anadromy in brook charr. Reviews in Fish Biology and Fisheries 20, 557-570. doi: 10.1007/s11160-010-9160-Z

Dalziel, A. C., Vines, T. H. \& Schulte, P. M. (2011). Reductions in prolonged swimming capacity following freshwater colonization in multiple threespine stickleback populations. Evolution 66, 1226-1239. doi: 10.1111/j.1558-5646.2011.01498.x

Derome, N., Bougas, B., Rogers, S. M., Whiteley, A. R., Labbe, A., Laroche, J. \& Bernatchez, L. (2008). Pervasive sex-linked effects on transcription regulation as revealed by expression quantitative trait loci mapping in lake whitefish species pairs (Coregonus sp., Salmonidae). Genetics 179, 1903-1917. doi: 10.1534/genetics.107.086306

Dobson, G. P. \& Hochachka, P. W. (1987). Role of glycolysis in adenylate depletion and repletion during work and recovery in teleost white muscle. Journal of Experimental Biology 129, $125-140$.

Drabkin, D. L. \& Austin, J. H. (1935). Spectrophotometric studies. II. Preparations from washed blood cells; nitric oxide heamoglobin and sulfhemoglobin. Journal of Biological Chemistry 112, 51-65.

Edmands, S. (1999). Heterosis and outbreeding depression in interpopulation crosses spanning a wide range of divergence. Evolution 53, 1757-1768. doi: 10.2307/2640438

Eliason, E. J. \& Farrell, A. P. (2016). Oxygen uptake in Pacific salmon Oncorhynchus spp.: when ecology and physiology meet. Journal of Fish Biology 88, 359-388. doi: $10.1111 /$ jfb. 12790

Eliason, E. J., Clark, T. D., Hague, M. J., Hanson, L. M., Gallagher, Z. S., Jeffries, K. M., Gale, M. K., Patterson, D. A., Hinch, S. G. \& Farrell, A. P. (2011). Differences in thermal tolerance among sockeye salmon populations. Science 332, 109-112. doi: 10.1126/science. 1199158

Eliassen, R. A., Johnsen, H. K., Mayer, I. \& Jobling, M. (1998). Contrasts in osmoregulatory capacity of two Arctic charr, Salvelinus alpinus (L.), strains from northern Norway. Aquaculture 168, 255-269. doi: 10.1016/S0044-8486(98)00353-6

Ellegren, H. \& Parsch, J. (2007). The evolution of sex-biased genes and sex-biased gene expression. Nature Reviews Genetics 8, 689-698. doi: 10.1038/Nrg2167

Ellner, S. P., Geber, M. A. \& Hairston, N.G. (2011). Does rapid evolution matter? Measuring the rate of contemporary evolution and its impacts on ecological dynamics. Ecology Letters 14, 603-614. doi: 10.1111/j.1461-0248.2011.01616.x

Emlen, J. M. (1991). Heterosis and outbreeding depression - a multilocus model and an application to salmon production. Fisheries Research 12, 187-212. doi: 10.1016/0165-7836 (91) $90095-\mathrm{W}$

Evans, J. P., Kellay, J. L., Bisazza, A., Finazzo, E. \& Pilastro, A. (2004). Sire attractiveness influences offspring performance in guppies. Proceedings of the Royal Society B 271, 2035-2042. doi: 10.1098/rspb.2004.2815

Falconer, D. S. \& Mackay, T. F. C. (1996). Introduction to Quantitative Genetics. Harlow: Longman Group.

Falica, B. K. \& Higgs, D. M. (2012). Paternal genetic effect on offspring swimming performance vary with of juvenile Chinook salmon Oncorhynchus tshawytscha. Evolutionary Biology, doi: 10.1007/s11692-012-9217-0

Fraser, D. J. \& Bernatchez, L. (2005). Adaptive migratory divergence among sympatric brook charr populations. Evolution 59, 611-624. doi: 10.1554/04-346

Fu, S. J., Brauner, C. J., Cao, Z. D., Richards, J. G., Peng, J. L., Dhillon, R. \& Wang, Y. $X$. (2011). The effect of acclimation to hypoxia and sustained exercise on subsequent hypoxia tolerance and swimming performance in goldfish (Carassius auratus). Journal of Experimental Biology 214, 2080-2088. doi: 10.1242/jeb.053132

Gamperl, A. K., Rodnick, K. J., Faust, H. A., Venn, E. C., Bennett, M. T., Crawshaw, L. I., Keeley, E. R., Powell, M. S. \& Li, H. W. (2002). Metabolism, swimming performance and tissue biochemistry of high desert redband trout (Oncorhynchus mykiss spp.): evidence for phenotypic differences in physiological function. Physiological and Biochemical Zoology 75, 413-431. doi: 10.1086/343139 
Granier, S., Audet, C. \& Bernatchez, L. (2011). Evidence for both heterosis and outbreeding depression in growth of young-of-the year brook charr (Salvelinus fontinalis). Canadian Journal of Zoology - Revue Canadienne De Zoologie 89, 190-198. doi: 10.1139/Z10-108

Hawkins, D. K. \& Quinn, T. P. (1996). Critical swimming velocity and associated morphology of juvenile coastal cutthroat trout (Oncorhynchus clarki clarki), steelhead trout (Oncorhynchus mykiss) and their hybrids. Canadian Journal of Fisheries and Aquatic Sciences 53, 1487-1496. doi: 10.1139/f96-085

Heath, D. D., Fox, C. W. \& Heath, J. W. (1999). Maternal effects on offspring size: variation through early development of Chinook salmon. Evolution 53,1605-1611. doi: $10.2307 / 2640906$

Henry, R. J. (1968). Clinical Chemistry - Principles and Techniques. New York, NY: Harper \& Row.

Howland, K. L., Tonn, W. M. \& Goss, G. (2001). Contrasts in the hypo-osmoregulatory abilities of a freshwater and an anadromous population of inconnu. Journal of Fish Biology 59, 916-927. doi: 10.1111/j.1095-8649.2001.tb00161.x

Jain, K. E., Birtwell, I. K. \& Farrell, A. P. (1998). Repeat swimming performance of mature sockeye salmon following a brief recovery period: a proposed measure of fish health and water quality. Canadian Journal of Zoology -Revue Canadienne De Zoologie 76, 1488-1496. doi: 10.1139/z98-079

Kitano, J., Ishikawa, A., Kume, M. \& Mori, S. (2012). Physiological and genetic basis for variation in migratory behavior in the three-spined stickleback, Gasterosteus aculeatus. Ichthyological Research 59, 293-303, doi: 10.1007/s10228-012-0289-8

Klemetsen, A., Amundsen, P. A., Dempson, J. B., Jonsson, B., Jonsson, N., O'Connell, M. F. \& Mortense, E. (2003). Atlantic salmon Salmo salar L., brown trout Salmo trutta L. and Artic charr Salvelinus alpinus (L.): a review of aspects of their life histories. Ecology of Freshwater Fish 12, 1-59. doi: 10.1034/j.1600-0633.2003.00010.x

Le François, N. R. \& Blier, P. U. (2003). Reproductive events and associated reduction in the seawater adaptability of brook charr (Salvelinus fontinalis): evaluation of gill metabolic adjustments. Aquatic Living Resources 16, 69-76. doi: 10.1016/S0990-7440(03)00009-3

Lee, C. G., Farrell, A. P., Lotto, A., MacNutt, M. J., Hinch, S. G. \& Healey, M. C. (2003). The effect of temperature on swimming performance and oxygen consumption in adult sockeye (Oncorhynchus nerka) and coho (O. kisutch) salmon stocks. Journal of Experimental Biology 206, 3239-3251. doi: 10.1242/jeb.00547

MAPA-Pêcheries, D. R. S. T. (1992). Mission d'exploration à la Baie James (Lac Némiscau - Rivière Rupert) pour la construction d'une lignée de référence d'omble de fontaine, Salvelinus fontinalis. Doc. Rech., pp. 32.

Marras, S., Killen, S. S., Domenici, P., Claireaux, G. \& McKenzie, D. (2013). Relationships among traits of aerobic and anaerobic swimming performance in individual European sea bass Dicentrarchus labrax. PLoS One 8, e72815. doi: 10.1371/journal.pone.0072815

Martin, S., Savaria, J.-Y., Audet, C. \& Bernatchez, L. (1997). Microsatellites reveal no evidence for inbreeding effects but low inter-stock genetic diversity among brook charr stocks used for production in Quebec. Bulletin of the Aquaculture Association of Canada 97, 21-23.

McDowall, R. M. (1997). The evolution of diadromy in fishes (revisited) and its place in phylogenetic analysis. Reviews in Fish Biology and Fisheries 7, 443-462. doi: 10.1023/A: 1018404331601

McKenzie, D. J., Cataldi, E., Romano, P., Owen, S. F., Taylor, E. W. \& Bronzi, P. (2001a). Effects of acclimation to brackish water on the growth, respiratory metabolism and swimming performance of young-of-the-year Adriatic sturgeon (Acipenser naccarii). Canadian Journal of Fisheries and Aquatic Sciences 58, 1104-1112. doi: 10.1139/cjfas-58-6-1104

McKenzie, D. J., Cataldi, E., Romano, P., Taylor, E. W., Cataudella, S. \& Bronzi, P. $(2001 b)$. Effects of acclimation to brackish water on tolerance of salinity challenge by young-of-the-year Adriatic sturgean (Acipenser naccarii). Canadian Journal of Fisheries and Aquatic Sciences 58, 1113-1121. doi: 10.1139/cjfas-58-6-1113

Milligan, C. L. (1996). Metabolic recovery from exhaustive exercise in rainbow trout. Comparative Biochemistry and Physiology Part A: Physiology 113, 51-60. doi: 10.1016/0300-9629(95)02060-8 
Morinville, G. R. \& Rasmussen, J. B. (2003). Early juvenile bioenergetic differences between anadromous and resident brook trout (Salvelinus fontinalis). Canadian Journal of Fisheries and Aquatic Sciences 60, 401-410. doi: 10.1139/F03-036

Morinville, G. R. \& Rasmussen, J. B. (2008). Distinguishing between juvenile anadromous and resident brook trout (Salvelinus fontinalis) using morphology. Environmental Biology of Fishes 81, 171-184. doi: 10.1007/s10641-007-9186-9

Nelson, J. A., Tang, Y. \& Boutilier, R. G. (1996). The effects of salinity change on the exercise performance of two Atlantic cod (Gadus morhua) populations inhabiting different environments. Journal of Experimental Biology 199, 1295-1309.

Odell, J. P., Chappell, M. A. \& Dickson, K. A. (2003). Morphological and enzymatic correlates of aerobic and burst performance in different populations of Trinidadian guppies Poecilia reticulata. Journal of Experimental Biology 206, 3707-3718. doi: 10.1242/Jeb.00613

Peake, S., McKinley, R. S. \& Scruton, D. A. (1997). Swimming performance of various freshwater Newfoundland salmonids relative to habitat selection and fishway design. Journal of Fish Biology 51, 710-723. doi: 10.1111/j.1095-8649.1997.tb01993.x

Pearse, D. E., Hayes, S. A., Bond, M. H., Hanson, C. V., Anderson, E. C., Macfarlane, R. B. \& Garza, J. C. (2009). Over the falls? Rapid evolution of ecotypic differentiation in steelhead/rainbow trout (Oncorhynchus mykiss). Journal of Heredity 100, 515-525. doi: 10.1093/jhered/esp040

Perry, G. M. L., Audet, C., Laplatte, B. \& Bernatchez, L. (2004). Shifting patterns in genetic control at the embryo-alevin boundary in brook charr. Evolution 58, 2002-2012. doi: $10.1554 / 03-721$

Perry, G. M. L., Audet, C. \& Bernatchez, L. (2005). Maternal genetic effects on adaptive divergence between anadromous and resident brook charr during early life history. Journal of Evolutionary Biology 18, 1348-1361. doi: 10.1111/j.1420-9101.2005.00954.x

Pon, L. B., Hinch, S. G., Wagner, G. N., Lotto, A. G. \& Cooke, S. J. (2007). Swimming performance and morphology of juvenile sockeye salmon, Oncorhynchus nerka: comparison of inlet and outlet fry populations. Environmental Biology of Fishes 78, 257-269. doi: 10.1007/s10641-006-9094-4

Quinn, G. P. \& Keough, M. J. (2002). Experimental Design and Data Analysis for Biologists. Cambridge: Cambridge University Press.

Redjah, I., Olivier, F., Tremblay, R., Myrand, B., Pernet, F., Neumeier, U. \& Chevarie, L. (2010). The importance of turbulent kinetic energy on transport of juvenile clams (Mya arenaria). Aquaculture 307, 20-28. doi: 10.1016/j.aquaculture.2010.06.022

Reznick, D. N., Shaw, F. H., Rodd, H. \& Shaw, R. G. (1997). Evaluation of the rate of evolution in natural populations of guppies (Poecilia reticulata). Science 275, 1934-1937. doi: 10.1126/science.275.5308.1934

Rosenfield, J. A., Nolasco, S., Lindauer, S., Sandoval, C. \& Kodric-Brown, A. (2004). The role of hybrid vigor in the replacement of Pecos pupfish by its hybrids with sheepshead minnow. Conservation Biology 18, 1589-1598. doi: 10.1111/j.1523-1739.2004.00356.x

Sauvage, C., Derôme, N., Normandeau, E., Cyr, J. S., Audet, C. \& Bernatchez, L. (2010). Fast transciptional response to domestication in the brook charr Salvelinus fontinalis. Genetics 185, 1-8. doi: 10.1534/genetics.110.115071

Seigler, L., D'Cotta, H., Paulin, L., Baglinière, J. L. \& Prunet, P. (1996). Biopsie et mesure de l'activité $\mathrm{Na}^{+} \mathrm{K}^{+}$ATPasique branchiale: validité et impact sur le développement du smolt de saumon Atlantique (Salmo Salar L.). Bulletin Francais de la Peche et de la Pisciculture 340, 43-55.

Sokal, R. R. \& Rohlf, F. J. (1981). Biometry: The Principles and Practice of Statistics in Biological Research. San Francisco, CA: W. H. Freeman.

Stelkens, R. B., Schmid, C., Selz, O. \& Seehausen, O. (2009). Phenotypic novelty in experimental hybrids is predicted by the genetic distance between species of cichlid fish. BMC Evolutionary Biology 9, 283. doi: 10.1186/1471-2148-9-283

Taylor, E. B. \& Foote, C. J. (1991). Critical swimming velocities of juvenile sockeye salmon and kokanee, the anadromous and non-anadromous forms of Oncorhynchus nerka (Walbaum). Journal of Fish Biology 38, 407-419. doi: 10.1111/j.1095-8649.1991.tb03130.x

Taylor, E. B. \& McPhail, J. D. (1985). Variation in burst and prolonged swimming performance among British Columbia populations of coho salmon, Oncorhynchus kisutch. Canadian Journal of Fisheries and Aquatic Sciences 42, 2029-2033. 
Thériault, V., Bernatchez, L. \& Dodson, J. J. (2007). Mating system and individual reproductive success of sympatric anadromous and resident brook charr, Salvelinus fontinalis, under natural conditions. Behavioral Ecology and Sociobiology 62, 51-65. doi: $10.1007 / \mathrm{s} 00265-007-0437-8$

Tierney, K. B. \& Farrell, A. P. (2004). The relationships between fish health, metabolic rate, swimming performance and recovery in return-run sockeye salmon, Oncorhynchus nerka (Walbaum). Journal of Fish Diseases 27, 663-671. doi: 10.1111/j.1365-2761.2004. 00590.x

Tudorache et al, 2007. 2

Tudorache, C., Viaene, P., Blust, R., Vereecken, H. \& De Boeck, G. (2008). A comparison of swimming capacity and energy use in seven European freshwater fish species. Ecology of Freshwater Fish 17, 284-291. doi: 10.1111/j.1600-0633.2007.00280.x

Tymchuk, W., Sakhrani, D. \& Devlin, R. (2009). Domestication causes large-scale effects on gene expression in rainbow trout: analysis of muscle, liver and brain transcriptomes. General and Comparative Endocrinology 164, 175-183. doi: 10.1016/j.ygcen.2009.05.015

Vandeputte, M., Porte, J. D., Auperin, B., Dupont-Nivet, M., Vergnet, A., Valotaire, C., Claireaux, G., Prunet, P. \& Chatain, B. (2016). Quantitative genetic variation for post-stress cortisol and swimming performance in growth-selected and control populations of European sea bass (Dicentrarchus labrax). Aquaculture 455, 1-7. doi: 10.1016/j.aquaculture.2016.01.003

Wagner, G. N., Kuchel, L. J., Lotto, A., Patterson, D. A., Shrimpton, J. M., Hinch, S. G. \& Farrell, A. P. (2006). Routine and active metabolic rates of migrating adult wild sockeye salmon (Oncorhynchus nerka Walbaum) in seawater and fresh water. Physiological and Biochemical Zoology 79, 100-108. doi: 10.1086/498186

Wainwright, P. C., Alfaro, M. E., Bolnick, D. I. \& Husley, C. D. (2005). Many-to-one mapping of form to function: a general principle in organismal design? Integrative and Comparative Biology 45, 256-262. doi: 10.1093/icb/45.2.256

Walker, J. A. (2010). An integrative model of evolutionary covariance: a symposium on body shape in fishes. Integrative and Comparative Biology 50, 1051-1056. doi: 10.1093/icb/icq014

Westley, P. A. H., Ward, E. J. \& Fleming, I. A. (2013). Fine-scale local adaptation in an invasive freshwater fish has evolved in contemporary time. Proceedings of the Royal Society $B$ 280, 20122327. doi: 10.1098/rspb.2012.2327

Wood, C. M. (1991). Acid-base and ion balance, metabolism and their interactions, after exhaustive exercise in fish. Journal of Experimental Biology 160, 285-308.

Yang, Y., Cao, Z. D. \& Fu, S. J. (2015). Variations in temperature acclimation effects on glycogen storage, hypoxia tolerance and swimming performance with seasonal acclimatization in juvenile Chinese crucián carp. Comparative Biochemistry and Physiology Part A: Molecular \& Integrative Physiology 185, 16-23. doi: 10.1016/j.cbpa.2015.03.009

\section{Electronic Reference}

Bell, W. H. \& Terhune, L. D. B. (1970). Water tunnel design for fisheries research. Fisheries Research Board of Canada Technical Reports 195, pp. 1-69. Available at http://www.dfompo.gc.ca/Library/25190.pdf/ 